\title{
WORKING
}

paper

\section{Structural Estimation of Time- Varying Spillovers: an Application to International Credit Risk Transmission}

\section{Lukas Boeckelmann ${ }^{1}$, Arthur Stalla-Bourdillon ${ }^{2}$}

\author{
December 2020, WP 798
}

\begin{abstract}
We propose a novel approach to quantify spillovers on financial markets based on a structural version of the Diebold-Yilmaz framework. Key to our approach is a SVARGARCH model that is statistically identified by heteroskedasticity, economically identified by maximum shock contribution and that allows for time-varying forecast error variance decompositions. We analyze credit risk spillovers between EZ sovereign and bank CDS. Methodologically, we find the model to better match economic narratives compared with common spillover approaches and to be more reactive than models relying on rolling window estimations. We find, on average, spillovers to explain $37 \%$ of the variation in our sample, amid a strong variation of the latter over time. ${ }^{3}$
\end{abstract}

Keywords: CDS, spillover, sovereign debt, systemic risk, SVAR, identification by heteroskedasticity.

JEL classification: C58, G01, G18, G21

\footnotetext{
1 Paris School of Economics and Banque de France, lukas.boeckelmann@banque-france.fr

${ }^{2}$ Université Paris Dauphine and Banque de France, arthur.stalla-bourdillon@banque-france.fr

3 Acknowledgments and disclaimer: We thank Helmut Lütkepohl and George Milunovich for sharing their Matlab codes, as well as Roberto De Santis, Jean Imbs and Gaëlle le Fol for helpful comments. We also thank the participants of the following seminars: CFE 2018 in Pisa, Workshop ANR Multirisk 2019 in Florence, Internal PSE-Banque de France Workshop 2019 in Paris and DIW Macroeconometric Workshop in Berlin, as well as the PGCR and SIF services at Banque de France for their help with data collection. The views expressed in this paper are the authors' and should not be read or quoted as representing those of Banque de France or the Eurosystem. Potential errors are our own.
} 


\section{NON-TECHNICAL SUMMARY}

Assessing spillovers between financial assets is a difficult exercise. When a shock occurs in one market and then spreads to others, prices of those markets are affected in a quasicontemporary manner. It is difficult then, ex post, to identify the source of the shock and thus to distinguish correlation from causality in the movement of financial time series.

Moreover, the magnitude of the transmission of such shocks is not stable over the observed period. Therefore, a good spillover model should not only succeed in identifying the shocks in question, but also take into account the time-varying effects they have on other markets. Several papers in the literature have proposed to solve this problem by estimating models on rolling windows. However, this methodology has downsides: in rolling windows new observations have little weight compared to past observations, so that such model lack in responsiveness.

In this paper, we propose a novel model to quantify spillovers based on the work of Diebold and Yilmaz (2009) and Lütkepohl and Milunovich (2016). We estimate this model on sovereign and bank Credit Default Swaps (CDS) in the Eurozone. More specifically, we use this methodology to assess the national and international propagation of credit risk shocks and to analyze the extent of the sovereign-bank nexus across countries.

Our main results are methodological. By comparing our estimates with those of other models used in the literature, we observe a superior performance of our methodology with respect to the two issues mentioned: the identification of shocks and the reactivity to new events. Concerning the identification of shocks, we compare the capacity of the models to clearly distinguish between bank and sovereign shocks. For example, during the Italian political crisis of May 2018, Italian bank and sovereign CDS spreads increased significantly at the same time, thus reinforcing the likelihood for any spillover model to mistake this sovereign shock for a bank shock. As shown in the graph below, for this particular event the SVARGARCH model we propose is the only one correctly identifying the shock. Analysing the performance more generally on a large list of bank and sovereign events, the SVAR-GARCH compares favourable to competing models. Concerning the reactivity of spillover estimates, we compare the different methodologies by performing Granger causality tests. We find that the estimates produced by the SVAR-GARCH model are more reactive, especially compared to models estimated on rolling windows.

We also present economic results that further support our identification strategy: The spillovers the model produces retrace well the Eurozone crisis; for example by underlining the importance of Irish shocks at the beginning of the crisis, followed by a rise of Italian and Spanish shocks. Moreover, we find that the spillover estimates are positively associated with channels of credit risk transmission that the theoretical and empirical literature suggests.

All in all, the model we propose appears well suited for estimating spillovers between CDS markets, combining an attractive identification approach with time variation in the spillover estimates, while contributing to the active literature on methodologies for spillover estimations. Moreover, to the extent that our model imposes relatively few restrictions, it lends itself to be a useful tool for the analysis of spillover dynamics on a broad set of financial markets, instruments and variables. 
Spillover indices from Italian shocks (sovereign and bank)
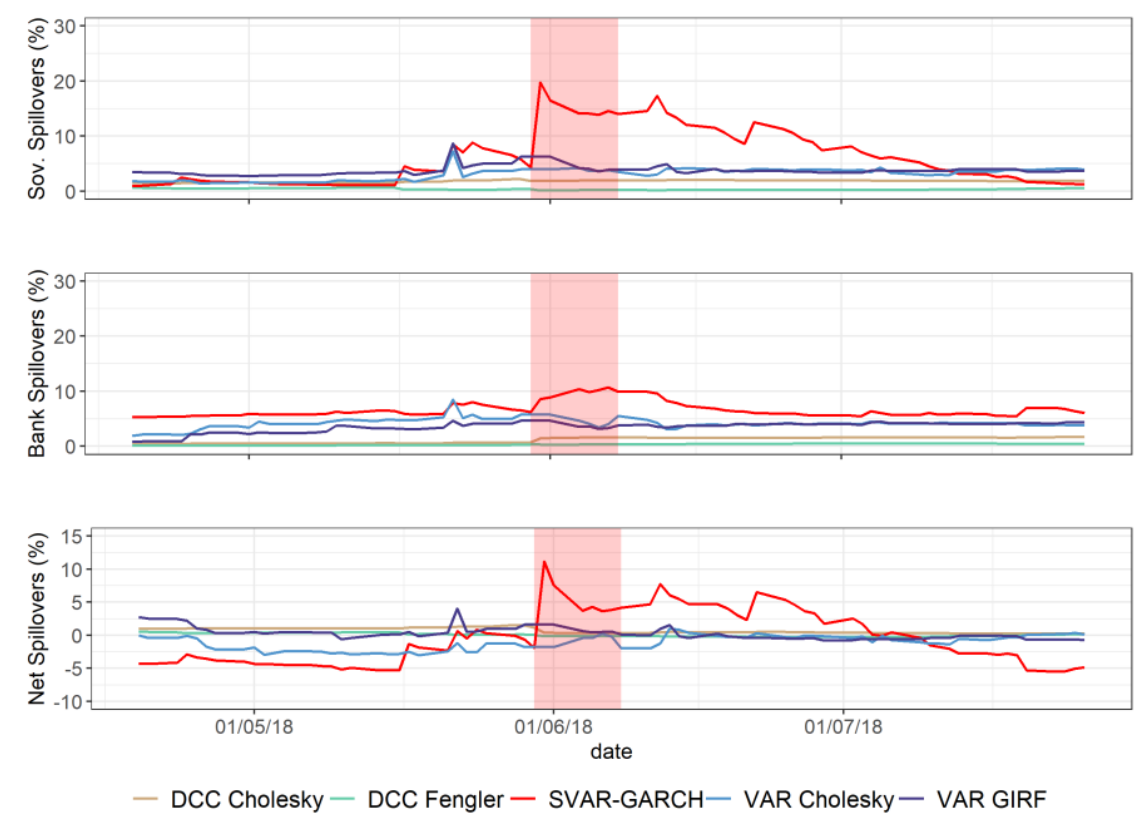

Note: The upper and middle parts of the graph represent spillover indices from Italian sovereign and bank shocks (i.e. how much the latter affect the variances of other variables). The lower part of the graph represents the difference between Italian sovereign and bank spillovers. The vertical red bar highlights the period of May 2018, when Italy was rattled by political turmoil. The models represented correspond to the following references: our paper (SVAR-GARCH), Diebold and Yilmaz (2009, VAR Cholesky), Diebold and Yilmaz (2012, VAR GIRF), Fengler and Herwartz (2018, DCC Fengler), and a contagion model built on Engle (2002, DCC Cholesky).

\section{Estimer de manière non-constante les contagions financières : une application à la transmission de chocs sur le risque de crédit}

\section{RÉSUMÉ}

Nous proposons une nouvelle méthodologie pour estimer les contagions financières à l'aide d'une version structurelle de l'approche de Diebold-Yilmaz. Le cœur de notre approche repose sur un modèle SVAR-GARCH qui est identifié par hétéroscédasticité et par la contribution maximale des chocs, et qui permet d'obtenir des décompositions non-constantes de la variance des erreurs de prévision. Nous analysons les contagions entre les CDS souverains et bancaires de la Zone Euro. En termes de méthodologie, nous trouvons que notre modèle permet de mieux identifier les chocs par rapport aux autres approches de la littérature, et qu'il est aussi plus réactif que les modèles estimés sur fenêtres glissantes. Nous trouvons, en moyenne, que la contagion explique $37 \%$ de la variation des séries de notre échantillon, avec toutefois de fortes variations dans le temps.

Mots-clés:CDS, contagion, dette souveraine, risque systémique, SVAR, identification par hétéroscédasticité.

Les Documents de travail reflètent les idées personnelles de leurs auteurs et n'expriment pas nécessairement la position de la Banque de France. Ils sont disponibles sur publications.banque-france.fr 


\section{Introduction}

Assessing financial spillovers between different markets can be highly challenging. To evaluate how a specific shock propagated from one market to another requires first to identify this shock. Yet, this task may cause significant difficulties as asset prices contemporaneously affect each other and thus co-move significantly. As for numerous asset classes, this problem applies to spillovers of credit risk; itself a topic of substantial interest for both researchers and policy makers due to their pivotal role in the European debt crisis (Coeuré (2018)).

A recent example for credit risk contagion ${ }^{1}$ that has lead to asset price comovement is the political turmoil in Italy and heightened fear of a referendum on the Euro membership in May $2018^{2}$. The event, which can be interpreted as a sovereign Italian shock, led to a considerable surge in the Italian sovereign CDS spreads, a proxy for credit risk. This shock then propagated to Italian bank CDS as well as to CDS of other Euro Area sovereigns and banking sectors, for example in Spain (Figure 1 presents daily CDS of the Euro Area sovereigns and banking sector, the red bar indicates the peak of the political turmoil). As can be seen from Figure 1 the daily CDS series increased simultaneously, therefore a mere visual analysis of Figure 1 cannot help to identify the source of the upsurge: was it a sovereign or a bank shock, and originating from which country? This example highlights the two main needed features of an econometric model with the aim to capture credit risk spillovers. First, the estimated model should be able to handle endogeneity and strong asset co-movements. Second, spillover estimates need to reflect the time variation in financial spillovers as these latter are unlikely to stay constant over time.

The main contribution of this paper is to combine an attractive identification approach

\footnotetext{
${ }^{1}$ Here, we use the terms spillover and contagion interchangeably. Section 2 differentiates more clearly between the concepts.

${ }^{2}$ See FT: https://www.ft.com/content/eed97b90-6306-11e8-90c2-9563a0613e56
} 
Figure 1: Sovereign and bank CDS spreads for Italy and Spain

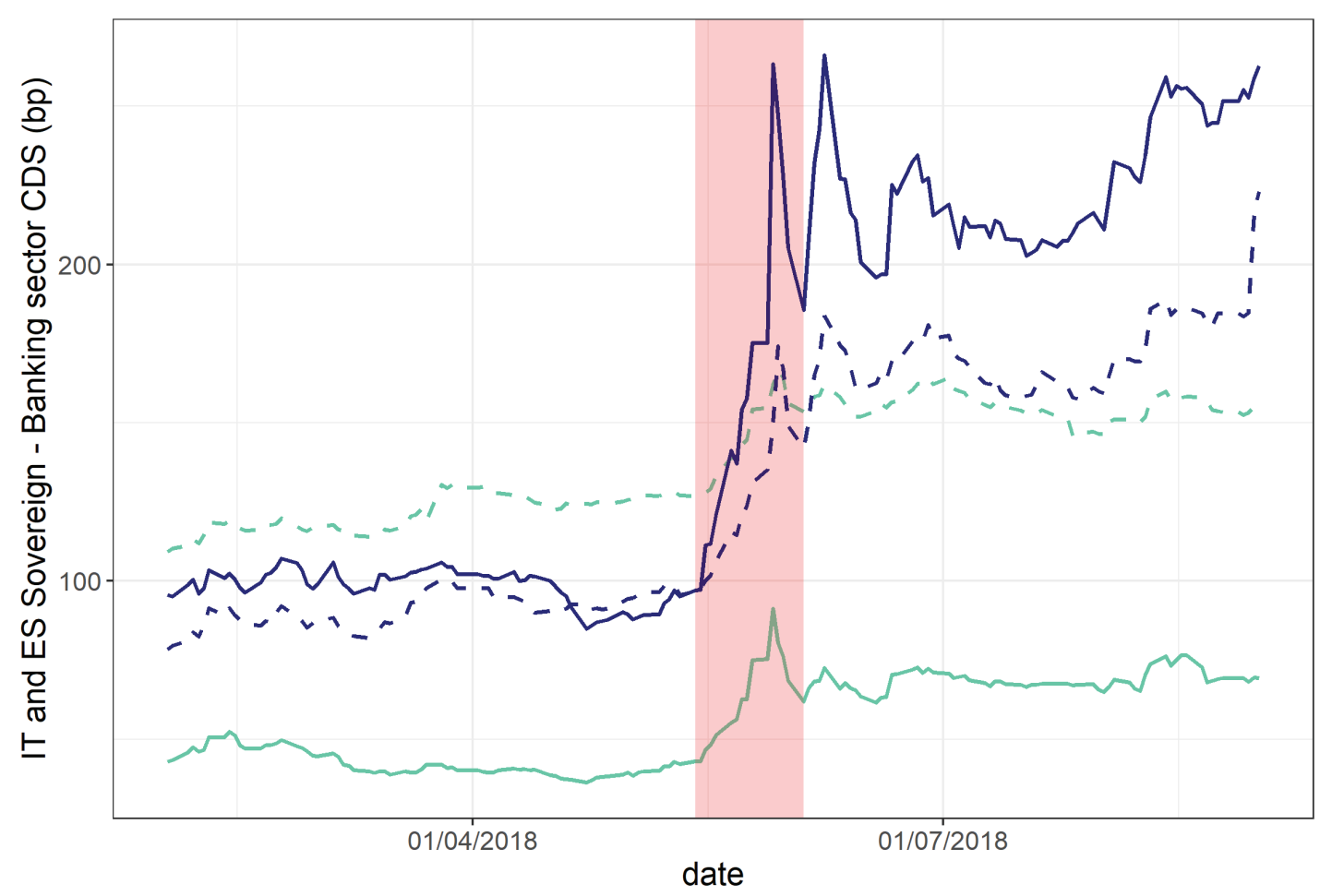

- ES banking sector - ES sovereign - IT banking sector - IT sovereign

On the graph are represented the CDS spreads from the Italian and Spanish sovereign and banking sectors (dashed lines). The red bar indicates the peak of the Italian political turmoil. The sources of the data and the underlying methodology can be found in Section 4.

for a set of endogenous variables with time variation in the estimates of the spillovers. To do so, we rely on a SVAR-GARCH approach combined with the framework of Diebold and Yilmaz (2009). As an application, we estimate the model on a sample of 16 banking sector and sovereign CDS series in the Eurozone (EZ), including the CDS series presented in Figure 1. First, we show that economic identification of the shocks is feasible in this framework, even in a 16-variable system. Second, we test and validate that the economic channels behind the estimates fit economic theories on financial contagion.

The seminal work by Diebold and Yilmaz (2009), as well as a large number of subsequent papers (Alter and Beyer (2014); Claeys and Vašíček (2014); De Santis and Zimic 
(2018); Demirer et al. (2018)), propose to base spillover estimates on the off-diagonal entries of forecast error variance decompositions (FEVDs) of rolling window structural vector autoregressions (SVARs). While the approach allows for the construction of mutual consistent spillovers, the literature faces the econometric challenge of identification (De Santis and Zimic (2018)). Earlier papers rely on short-run zero restrictions for the coefficients of the SVAR. However this assumption is unlikely to hold with very reactive financial data (see Alter and Beyer (2014)). Later papers sidestep any structural identification by using reduced form shocks in the form of Generalized FEVD analysis (GFEVD, see Pesaran and Shin (1998)). Yet, reduced form shocks have no economic interpretation and cannot be used for quantifying causal relationships of the data (Kilian and Lütkepohl (2017)). Other standard identification approaches are not appealing either: sign restrictions (Fry and Pagan (2011)), for example, are not exploitable as we do not want to restrict the impacts of the shocks a priori. De Santis and Zimic (2018) and De Santis and Zimic (2019) propose attractive identification schemes using magnitude restrictions. However, as most of the literature, they rely on rolling window estimations in order to generate time variation in their spillover estimates. Such rolling window estimations come with a significant drawback: at each point in time they deliver average effects over large time spans where new events are drown in past data. Spillover estimates therefore do not represent up-to-date information.

We propose a novel approach on handling such econometric modeling choices by exploiting a SVAR-GARCH model that is statistically identified by the heteroskedasticity in the data (Lütkepohl and Milunovich (2016)). We show that this modelization is also attractive as it yields time-varying FEVDs based on the conditional variances of estimated structural errors. To the best of our knowledge, we are the first to exploit the timevarying properties of the conditional variances for Diebold-Yilmaz spillover estimates in a SVAR-GARCH setting. Moreover, we show that it is feasible to achieve economic identification between structural shocks and financial market variables in a nontrivial 
one-to-one relationship, even in a system of 16 variables. We label shocks with a maximum contribution to the forecast error variance of a variable as a shock of precisely that variable (following the 3 to 4 -variable identification of Grosse Steffen and Podstawski (2016) and Dungey et al. (2010)). Due to the GARCH component in our estimation, spillover estimates are up-to-date (as in Fengler and Herwartz (2018)) and not drown in a moving window average (as in Diebold and Yilmaz (2009, 2012, 2014)).

We present both methodological as well as economic results. First on the methodological side, we show that the identification of the SVAR-GARCH model yields shock estimates that fit known economic and market events, thus supporting the initial maximum contribution identification. We manage to match major shocks to credit risk to 117 news events, either for bank or for sovereign CDS. In a second step, building either on this list of events or on the lists used in Candelon et al. (2011) and Alexandre et al. (2016), we compare the economic match of the spillovers implied by the SVAR-GARCH to a wide range of different DY-models. We find that the SVAR-GARCH outperforms, on this measure, identification schemes used in Fengler and Herwartz (2018), Diebold and Yilmaz (2009) or Diebold and Yilmaz (2012). Third, we show that the SVAR-GARCH yields more up-to-date spillover estimates compared to traditional moving window estimates as it Granger causes the latter.

Economically, we find cross-section results that corroborate our identification strategy as spillover estimates match (i) the economic narratives of the EZ debt crisis and (ii) economic contagion channels proposed by the theoretical and empirical literatures. For example, we find that during the European debt crisis, spillovers from periphery countries increased markedly, while elevated spillovers from core countries are more centered around the 2008/09 financial crisis. As for the underlying economic channels, we find international credit risk spillovers between sovereigns to be higher when the two countries have stronger ties in trade and portfolio investments, in line with the business 
cycle network literature (Foerster et al. (2011)). We also find international credit risk spillovers between banking systems to be higher when they exhibit more similar portfolios; yet we find spillovers not to be significantly associated with bank cross-holdings (as suggested in Brunetti et al. (2019)). Concerning the national sovereign-bank nexuses, we find that (i) a lower capital ratio and higher debt to GDP ratio increase domestic bank to sovereign spillovers in both low and high debt countries; while (ii) reliance of the non bank sector on domestic bank funding is significantly associated with domestic bank to sovereign spillovers only in low debt countries. In turn, we find domestic sovereign to bank spillovers to be higher for countries with a stronger bank exposure to domestic government debt. Moreover, we find that in high debt countries domestic sovereign to bank spillover are stronger when the domestic banking sector shows higher non-performing loan ratios and disposes of a lower share of liquid assets to short term liabilities.

Overall, we find credit risk in the Euro Area to be less integrated than suggested by estimates based on the more standard Diebold-Yilmaz style VAR models. We estimate that, on average, credit risk spillovers explain about $37 \%$ of the total variation in our sample. Yet, we show that the importance of spillover fluctuates distinctively, peaking at $61 \%$.

\section{Estimating Contagion in the Literature}

Throughout this paper, we define spillovers as the degree to which exogenous shocks to one CDS market drive the variation of CDS spreads in other markets, in line with the FEVD-analysis of Diebold and Yilmaz (2009). Note however, that the definition of spillovers may differ in the literature. De Santis and Zimic (2018) characterize spillovers as the impulse response of one shock to another variable (hence taking into account the 
sign and not only the magnitude of the impact) while they label FEVD-estimates as "connectedness" and the coefficient estimates of their SVAR purged from the size-effect of the shocks as "contagion". Similarly, Claeys and Vašíček (2014) and Dungey et al. (2015) term contagion as significant changes in the propagation mechanism, not the propagation mechanism itself.

Diebold and Yilmaz $(2009,2012,2014)$ propose in a set of papers a prominent approach to quantify time-varying spillovers on financial markets. The model is widely reused in the literature (e.g. Claeys and Vašíček (2014), Alter and Beyer (2014), Fengler and Gisler (2015), Diebold et al. (2018), Hale and Lopez (2018), Greenwood-Nimmo et al. (2017) or Greenwood-Nimmo et al. (2019)). Yet the Diebold-Yilmaz approach relies on orthogonalized SVARs and the identification of the latter is challenging.

Three different streams of the contagion-literature do offer attractive identification strategies. First, De Santis and Zimic (2018) and De Santis and Zimic (2019) apply a methodology close to ours. They gauge the interconnectedness among sovereign debt markets or between medium-term interest rates with a Diebold-Yilmaz approach based on a SVAR that is identified by "magnitude restrictions", that is by imposing that a shock stemming from one country impacts the most its own country. Second, Ando et al. (2018) add numerous exogenous variables to their vector autoregressions with the aim to purge their variables from common factors. Once this filtering is done, they obtain (quasi) orthogonal shocks. Finally, several papers focusing on financial spillovers (Ehrmann et al. (2011), Dungey et al. (2015), Ehrmann and Fratzscher (2017), Fratzscher and Rieth (2019)) apply the idea of Rigobon (2003) and rely on the identification by heteroskedasticity. The authors use the variations in the variance-covariance matrix of the reduced form shocks to identify the structural shocks.

However, the time variation in the first two streams of the literature comes from a rolling window estimation. These papers use relatively long window length in order to have a 
sufficient accuracy in their parameter estimates. Nevertheless, with this feature, their models will lack responsiveness as past observations mitigate the effect of new ones. The third stream of the literature focuses on specific sub-periods (e.g. Ehrmann and Fratzscher (2017) or Dungey et al. (2015)) and do not provide a continuous estimation of their spillover indices.

In contrast, a recent literature has exploited MGARCH models that are capable of generating up-to-date spillovers (Fengler and Herwartz (2018), Strohsal and Weber (2015)). However, these models lack attractive identification approaches for structural analysis ${ }^{3}$. The same drawback applies to variation of the approach using time-varying VARs as in Geraci and Gnabo (2018) or in Korobilis and Yilmaz (2018).

\section{Methodology}

\subsection{Measuring spillovers}

We follow the key idea of Diebold and Yilmaz $(2009,2012,2014)$ and base a set of mutual consistent spillover measures, from pairwise to system wise, on FEVDs. Table 1 depicts a FEVD which is amended with an additional bottom row that captures the off-diagonal column sums, an additional column on the right that captures the off-diagonal row sums and a bottom right element that captures the grand average of either off-diagonal column or row sums.

The FEVD is populated by elements $d_{i j}^{H}$, which give the proportion of the $H$ step forecast error variance of variable $y_{j}$ that is driven by an orthogonal shock to $y_{i}$. Following

\footnotetext{
${ }^{3}$ For example, in Fengler and Herwartz (2018) the orthogonalisation is based on the square root of the variance-covariance matrix of the reduced form shocks. Thus it does not rely on economic intuition and therefore makes the interpretation of the structural shocks difficult.
} 
Table 1: Diebold-Yilmaz Spillover Table

\begin{tabular}{cccccc}
\hline & $y_{1}$ & $y_{2}$ & $\cdots$ & $y_{N}$ & To Others \\
\hline$y_{1}$ & $d_{11}^{H}$ & $d_{12}^{H}$ & $\cdots$ & $d_{1 N}^{H}$ & $\sum_{j=1}^{N} d_{1 j}^{H}, j \neq 1$ \\
$y_{2}$ & $d_{21}^{H}$ & $d_{22}^{H}$ & $\cdots$ & $d_{2 N}^{H}$ & $\sum_{j=1}^{N} d_{2 j}^{H}, j \neq 2$ \\
$\vdots$ & $\vdots$ & $\vdots$ & $\ddots$ & $\vdots$ & $\vdots$ \\
$y_{N}$ & $d_{N 1}^{H}$ & $d_{N 2}^{H}$ & $\cdots$ & $d_{N N}^{H}$ & $\sum_{j=1}^{N} d_{N j}^{H}, j \neq N$ \\
\hline \multirow{3}{*}{ From Others } & $\sum_{i=1}^{N} d_{i 1}^{H}$ & $\sum_{i=2}^{N} d_{i 2}^{H}$ & $\cdots$ & $\sum_{i=3}^{N} d_{i 3}^{H}$ & $\frac{1}{N} \sum_{i, j=1}^{N} d_{i j}^{H}$ \\
& $i \neq 1$ & $i \neq 2$ & & $i \neq N$ & $i \neq j$ \\
\hline
\end{tabular}

Diebold and Yilmaz $(2009,2012,2014)$ we define $d_{i j}^{H}$ as a pairwise directed spillover from $i$ to $j$ :

$$
S_{i \rightarrow j}^{H}=d_{i j}^{H} .
$$

The pairwise spillovers allow to construct more aggregated spillover indices. For example, the off-diagonal column sums indicate to which degree the $H$ step forecast error variation of variable $y_{j}$ is driven by other variables in the system. Diebold and Yilmaz (2009, 2012, 2014) define therefore inward spillovers as:

$$
S_{j \leftarrow \bullet}^{H}=\sum_{\substack{i=1 \\ i \neq j}}^{N} d_{i j}^{H} .
$$

Vice versa, the off-diagonal row sums indicate to what degree variable $y_{j}$ drives the variation of all other variables in the system. Outward spillovers are therefore defined as:

$$
S_{j \rightarrow \bullet}^{H}=\sum_{\substack{i=1 \\ i \neq j}}^{N} d_{j i}^{H} .
$$


Total spillovers in the system are finally defined as average of inward or outward spillovers.

$$
S^{H}=\frac{1}{N} \sum_{\substack{i, j=1 \\ i \neq j}}^{N} d_{i j}^{H} .
$$

As underlined above, Diebold and Yilmaz (2009, 2012, 2014) estimate time-varying FEVDs based on moving window estimations of vector autoregressions, and identify the SVARs with orthogonalization strategies that can be challenged. The remainder of the paper outlines an approach that allows for a structural estimation of VAR parameters as well as for time-varying FEVDs that do not rely on rolling window estimations.

\subsection{Description of the Model}

For the development of a structural version of the Diebold-Yilmaz index, we rely on a SVAR model with a GARCH error structure and an identification by heteroskedasticity, similar in spirit to Normandin and Phaneuf (2004). We choose the model for the following reasons: first, a GARCH error structure appears a natural choice given that first differences of CDS, alike many other financial variables, show clustering of volatility over time and is therefore well approximated by GARCH processes. Second, the model has the property of time-varying conditional volatility of the errors, given the GARCH structure of the model. This property is crucial for the identification of structural shocks (Rigobon (2003)). Third, still relying on this property, we can construct time-varying FEVDs. This last feature allows us to estimate the model over the whole period, thus enabling more responsiveness compared to a time-varying FEVD based on a rolling estimation.

\section{SVAR identification through heteroskedasticity}

We base the empirical model on a structural vector autoregression of order $p$, that allows 
our variables to be determined simultaneously.

$$
\boldsymbol{B}_{0} \boldsymbol{Y}_{t}=\boldsymbol{\gamma}+\boldsymbol{B}_{1} \boldsymbol{Y}_{t-1}+\ldots+\boldsymbol{B}_{p} \boldsymbol{Y}_{t-p}+\boldsymbol{\epsilon}_{t}
$$

where $\boldsymbol{Y}_{t}$ is a vector containing the endogenous variables of interest, typically sovereign and bank sector CDS time series. The matrices $\boldsymbol{B}_{i}$ contain the contemporaneous and lagged effects of the endogenous variables. $\boldsymbol{\epsilon}_{t}$ denote structural errors with zero mean and an unconditional diagonal variance covariance matrix $\boldsymbol{\lambda}_{\epsilon}$. As the SVAR cannot be estimated directly, we first estimate a reduced form VAR:

$$
\boldsymbol{Y}_{t}=\boldsymbol{\beta}+\boldsymbol{A}_{1} \boldsymbol{Y}_{t-1}+\ldots+\boldsymbol{A}_{p} \boldsymbol{Y}_{t-p}+\boldsymbol{\mu}_{t}
$$

where the reduced form shocks $\boldsymbol{\mu}_{t}$ have zero mean and a non-diagonal variance covariance matrix $\boldsymbol{\Sigma}_{\mu}$. The structural errors $\boldsymbol{\epsilon}_{t}$ are then defined through $\boldsymbol{\mu}_{t}$ and the contemporaneous interaction matrix $\boldsymbol{B}_{0}$ :

$$
\boldsymbol{\epsilon}_{t}=\boldsymbol{B}_{0} \boldsymbol{\mu}_{t} \quad \Leftrightarrow \quad \boldsymbol{\mu}_{t}=\boldsymbol{B}_{0}^{-1} \boldsymbol{\epsilon}_{t}
$$

The well known VAR identification problem arises as we try to obtain estimates for the contemporaneous interaction matrix $\boldsymbol{B}_{0}$ from the relationship $\boldsymbol{\Sigma}_{\mu}=\boldsymbol{B}_{0}^{-1} \boldsymbol{\lambda}_{\epsilon} \boldsymbol{B}_{0}^{-1 \prime}$. Yet without further restrictions $\boldsymbol{B}_{0}$ is not identified since $\boldsymbol{\Sigma}_{\mu}$ provides only $\frac{N(N+1)}{2}$ equations for $N^{2}$ unknowns if we normalize $\boldsymbol{\lambda}_{\epsilon}=I$.

The SVAR-GARCH model we are using relies on Rigobon (2003) identification scheme that exploits the general heteroskedasticity in financial data. Suppose that the variances (or conditional variances) of $\boldsymbol{\mu}_{t}$ vary over time - implying that the structural error variance does too - while $\boldsymbol{B}_{0}$ is constant ${ }^{4}$. This feature implies that there is more than one volatility regime in the data, defined by a different reduced form variance-covariance

\footnotetext{
${ }^{4}$ In Annex A.6 we relax this assumption.
} 
matrix $\boldsymbol{\Sigma}_{\mu}(m)$. If there are $M$ different volatility regimes, then we have:

$$
\boldsymbol{\Sigma}_{\mu}(1)=\boldsymbol{B}_{0}^{-1} \boldsymbol{B}_{0}^{-1 \prime}, \quad \boldsymbol{\Sigma}_{\mu}(m)=\boldsymbol{B}_{0}^{-1} \boldsymbol{\lambda}_{m} \boldsymbol{B}_{0}^{-1 \prime}, m=2, \ldots, M
$$

where $\boldsymbol{\lambda}_{m}$ are the diagonal matrices of the structural shocks $\left(\boldsymbol{\lambda}_{1}\right.$ is normalized to $\left.\boldsymbol{I}\right)$. Lanne and Saikkonen (2007) show that $\boldsymbol{B}_{0}$ is locally uniquely determined if $\forall(k, l)$ $\in\{1, \ldots, K\}^{2}, k \neq l$, there is an index $j \in\{2, \ldots, M\}$ such that $\lambda_{j k} \neq \lambda_{j l}$, i.e. there is sufficient heterogeneity in the volatility changes.

\section{SVAR-GARCH}

Conditional heteroskedasticity can be modeled in different ways (see Lütkepohl and Netšunajev (2017a)). We rely on the methodology first proposed by Normandin and Phaneuf (2004) and assume that it is driven by GARCH processes. Similar models have been applied in Bouakez and Normandin (2010), Lütkepohl and Milunovich (2016) and Lütkepohl and Netšunajev (2017a).

We assume that the structural shocks are orthogonal and that their variances follow a univariate $\operatorname{GARCH}(1,1)$ process:

$$
\begin{gathered}
\epsilon_{k, t}=\sigma_{k, t \mid t-1} e_{k, t} \quad \text { where } \quad \boldsymbol{e}_{t} \sim \text { i.i.d. } \mathrm{N}\left(\mathbf{0}, \boldsymbol{I}_{N}\right) \text { and } \\
\sigma_{k, t \mid t-1}^{2}=\left(1-\gamma_{k}-g_{k}\right)+\gamma_{k}\left(\epsilon_{k, t-1}\right)^{2}+g_{k} \sigma_{k, t-1 \mid t-2}^{2}
\end{gathered}
$$

where $\gamma_{k}>0, g_{k} \geq 0, \gamma_{k}+g_{k}<1,1 \leqslant k \leqslant N$ so that the $\operatorname{GARCH}(1,1)$ processes are non-trivial.

Then, we can express the reduced form shocks as:

$$
\boldsymbol{\mu}_{t}=\boldsymbol{B}_{0}^{-1} \boldsymbol{\lambda}_{t \mid t-1}^{\frac{1}{2}} \boldsymbol{e}_{t}
$$


where:

$$
\boldsymbol{\lambda}_{t \mid t-1}=\left[\begin{array}{ccc}
\sigma_{1, t \mid t-1}^{2} & & 0 \\
& \cdots & \\
0 & & \sigma_{N, t \mid t-1}^{2}
\end{array}\right]
$$

is a $(\mathrm{N} \times \mathrm{N})$ diagonal matrix with the univariate GARCH processes on the diagonal. Therefore, the distribution of $\boldsymbol{\mu}_{t}$ conditional on past information has mean zero and a covariance matrix:

$$
\boldsymbol{\Sigma}_{\mu, t \mid t-1}=\boldsymbol{B}_{0}^{-1} \boldsymbol{\lambda}_{t \mid t-1} \boldsymbol{B}_{0}^{-1 \prime}
$$

Rigobon (2003) shows that for full (local) statistical identification, 2 different volatility regimes is enough. With a SVAR-GARCH we have $T$ (number of observations) different volatility "regimes". In this study, using daily CDS data between 2008 and 2019, this translates into more then 2800 regimes. We estimate the parameters of the SVARGARCH model by Maximum Likelihood as in Lütkepohl and Milunovich (2016).

Forecasts for FEVD

Estimates for time-varying conditional variance-covariance matrices allow us to construct FEVDs for each time period, i.e. for each day. Note that for the computation of FEVDs in each period $t$, one cannot take the actual estimated structural variances $\hat{\boldsymbol{\lambda}}_{t \mid t-1}$. Instead, we need to compute, by definition of the FEVD, in-sample forecasts for the structural variances $\boldsymbol{\lambda}_{t+h \mid t}^{*}$ conditional on the information set in $t$, as in Fengler and Herwartz (2018). Contrary to the approach in the latter, our matrix $\boldsymbol{B}_{0}$ is constant over time, so that the only change between a classic SVAR-FEVD and our approach is the computation of future structural variances.

We have with Equation 10:

$$
\sigma_{k, t+h \mid t+h-1}^{2}=\left(1-\gamma_{k}-g_{k}\right)+\gamma_{k}\left(\epsilon_{k, t+h-1}\right)^{2}+g_{k} \sigma_{k, t+h-1 \mid t+h-2}^{2}
$$


Taking conditional expectation at time $t$, with $h \geq 2$ :

$$
E_{t} \sigma_{k, t+h \mid t+h-1}^{2}=\left(1-\gamma_{k}-g_{k}\right)+\gamma_{k} \sigma_{k, t+h-1 \mid t}^{2}+g_{k} E_{t} \sigma_{k, t+h-1 \mid t+h-2}^{2}
$$

Using the law of iterated expectations, we get:

$$
E_{t} \sigma_{k, t+h \mid t}^{2}=\left(1-\gamma_{k}-g_{k}\right)+\gamma_{k} \sigma_{k, t+h-1 \mid t}^{2}+g_{k} E_{t} \sigma_{k, t+h-1 \mid t}^{2}
$$

That is:

$$
\sigma_{k, t+h \mid t}^{2}=\left(1-\gamma_{k}-g_{k}\right)+\left(\gamma_{k}+g_{k}\right) \sigma_{k, t+h-1 \mid t}^{2}
$$

We thus obtain $\boldsymbol{\lambda}_{t+h \mid t}^{*}$ for each $h$ as this matrix is diagonal and is only composed of the different $\sigma_{k, t+h \mid t}^{2}$. To build the FEVDs, we then first compute the MSPE. The $\boldsymbol{\Theta}_{i}$ matrices come from the Moving Average (MA) representation of the SVAR as detailed in Kilian and Lütkepohl (2017):

$$
\boldsymbol{Y}_{t+H}-\boldsymbol{Y}_{t+H \mid t}=\sum_{i=0}^{H-1} \boldsymbol{\Theta}_{i} \boldsymbol{\epsilon}_{t+H-i}
$$

With the structural variances estimated, we get:

$$
\begin{aligned}
M S P E_{t}(H) & =E_{t}\left(\boldsymbol{Y}_{t+H}-\boldsymbol{Y}_{t+H \mid t}\right)\left(\boldsymbol{Y}_{t+H}-\boldsymbol{Y}_{t+H \mid t}\right)^{\prime} \\
& =\sum_{i=0}^{H-1} \boldsymbol{\Theta}_{i} \boldsymbol{\lambda}_{t+H-i \mid t}^{*} \Theta_{i}^{\prime}
\end{aligned}
$$

We can then evaluate the contribution of shock $j$ to MSPE of $y_{k t}$ with the usual MSPEformula, the only difference with a classic SVAR is that variances of structural shocks 
are no longer normalized to 1 . With $\theta_{k j, h}$ the $k j^{\text {th }}$ element of $\boldsymbol{\Theta}_{h}$ :

$$
M S P E_{j, t}^{k}(H)=\theta_{k j, 0}^{2} \sigma_{j, t+H \mid t}^{2}+\ldots+\theta_{k j, H-1}^{2} \sigma_{j, t+1 \mid t}^{2}
$$

With:

$$
\operatorname{MSPE}_{t}^{k}(H)=\sum_{j=1}^{K} M S P E_{j, t}^{k}(H)
$$

We get:

$$
F E V D_{j, t}^{k}(H)=\frac{M S P E_{j, t}^{k}(H)}{M S P E_{t}^{k}(H)}
$$

Eventually the time-varying FEVDs enable to build the time-varying spillover indices, as explained in Section 3.1.

\section{Data and filtering for common shocks}

\subsection{Data}

We focus on credit risk of major EZ sovereigns and banks. We attempt to strike a balance between a sufficiently high coverage of important CDS markets and the limited number of variables our empirical approach allows. As a result, we limit the sample to 9 countries (Greece, Ireland, Italy, Portugal, Spain, Germany, France, Belgium and Netherlands). For each country we include two variables in the sample, sovereign credit risk and credit risk in the banking sector, except for Ireland and Greece where we lack banking credit risk series due to data constraints ${ }^{5}$. This leaves us with 16 variables all together.

As standard in this literature (see Greenwood-Nimmo et al. (2019)), we measure credit

\footnotetext{
${ }^{5}$ See Acharya et al. (2014) and Fratzscher and Rieth (2019).
} 
risk using CDS spreads on senior unsecured debt, modified-modified restructuring, mid spread and a maturity of 5 years $^{6}$. We retrieve CDS spreads for non-US sovereigns and US banks denominated in USD while CDS spreads for the US sovereign and European banks are denominated in EUR. Our sample covers daily data between January 2008 and March 2019, covering the GFC, European debt crisis and several sovereign and banking turbulence such as the Italian political turmoil of May 2018. We construct country banking variables as an unweighted average of bank CDS from that country as in Greenwood-Nimmo et al. (2017). In the selection of banks, we follow Alter and Beyer (2014) (while we exclude those banks that defaulted over the observation period). In line with the rest of the literature we first-difference the CDS series. A detailed list of the considered banks as well as descriptive graphs of the CDS series can be found in Annex A.2.

\subsection{Filtering for common shocks}

The literature agrees that global and regional variables may exert a common influence on credit spreads (Longstaff et al. (2011)). Ignoring such common shocks that have a simultaneous effect on different variables in an econometric analysis may result in an overestimation of contagion patterns. We would falsely attribute common shocks to the propagation of idiosyncratic shocks. We therefore follow Alter and Beyer (2014) in including the following set of pan-European credit risk factors, including (i) the Itraxx Europe index (which comprises investment grade rated European entities, reflecting the overall credit performance of the European real economy), (ii) the Itraxx Crossover index (which comprises below investment grade rated European entities, reflecting the lowerend credit performance of the European real economy), and (iii) the spread between the

\footnotetext{
${ }^{6}$ We combine data from three sources: we use principally Thomson Reuters Datastream and extend the sample backwards using growth rates extracted from CDS series from CMA. In case of missing values in the resulting data set, we retrieve growth rates on CDS spreads from Bloomberg.
} 
3-month EURIBOR and the 3-month EONIA swap (a proxy for funding liquidity conditions equivalent to the TED spread). Moreover, we control for the Eurostoxx 50 (the European stock market index), the VIX index (as a proxy for investors' risk aversion) and US and UK sovereign and banking CDS series (to account for foreign shocks).

We account for common shocks in a two-step approach. First, we regress each CDS series individually on a vector of common factors and then we run the SVAR-GARCH model specified in Section 3.2 on the obtained residuals, as in Dungey et al. $(2010)^{7}$. That is, in a first step, we filter first differences bank and sovereign CDS series by the following OLS regression:

$$
\Delta z_{j t}=\alpha_{j}+\Delta \boldsymbol{X}_{t}^{\prime} \boldsymbol{\beta}_{j}+y_{j t}
$$

where $\Delta z_{j t}$ represents the first difference of a CDS series $j$ in the sample, $\alpha_{j}$ is a constant and $\Delta \boldsymbol{X}_{t}$ is a vector of common factors in first differences. $y_{j t}$ contains the residuals of the regression and serves as input data for the SVAR-GARCH. Annex A.6 reports robustness checks using a smaller set of exogenous variables.

\section{Results}

In this section we present the results for the SVAR-GARCH model outlined above. We estimate the model with 2 lags as indicated by the information criteria from a simple VAR estimated on the same dataset. Moreover, in line with Diebold and Yilmaz (2009, 2012, 2014), we choose a forecast horizon for the FEVD of 10 days. In Section 5.1 we present the results of our identification approach, that is the labeling of structural shocks, as well as comparisons of timeliness and of identification performances between competing models. In Section 5.2 we present the economic results of our application.

\footnotetext{
${ }^{7}$ This approach is similar to including a vector of exogenous variables directly into the SVAR. Alter and Beyer (2014) find similar results between the two approaches. In our case, a two-step approach is preferable as we found that including a vector of exogenous variables in the SVAR-GARCH significantly increases the time to convergence.
} 


\subsection{Econometric results}

\subsubsection{Statistical and economic identification}

Statistical identification is achieved when the number of univariate GARCH components underlying the GARCH structure are larger or equal to N-1. That means that for full local identification we may have at most one series that is not well approximated by a GARCH process in order to have sufficient heteroskedasticity in the structural shocks. We follow the identification test proposed by Lanne and Saikkonen (2007) and reject fewer than N-1 GARCH processes in our sample (see Annex A.1).

However, full local identification implies only statistical identification up to sign changes and ordering. To make the orthogonal shocks economic meaningful we need to label them, ideally in such a way that each orthogonal shock corresponds to a different variable. In line with Grosse Steffen and Podstawski (2016), we label shocks with the maximum contribution to the forecast error variance of a variable as a shock from this particular variable (for example the German banking sector). Exact economic identification is obtained if for each CDS series there is only one structural shock with a maximum contribution to the forecast error variance of that specific CDS series. As we estimate one FEVD for each day we focus on average shock contributions over time. However the labelling would be exactly the same if we focus, at each point in time, on individual FEVDs. Table 2 reports a FEVD that is averaged over all time periods and for which shocks are labelled accordingly. It is clear from the diagonal of the table that each shock has a maximum contribution to a different CDS series, allowing a clear labelling of the orthogonal shocks.

Our economic identification approach receives further confirmation from the fact that the estimated structural time series of shocks $\left(\hat{\boldsymbol{\epsilon}}_{t}\right.$ in Equation 5) correspond to a large 
Table 2: Forecast error variance decomposition, average over time (\%)

\begin{tabular}{|c|c|c|c|c|c|c|c|c|c|c|c|c|c|c|c|c|}
\hline & BE bk & FR bk & DE bk & IT bk & NL bk & ES bk & PT bk & DE & $\mathrm{BE}$ & FR & GR & NL & ES & IT & PT & IE \\
\hline BE bk & 81 & 1 & 3 & 0 & 2 & 0 & 0 & 2 & 1 & 1 & 0 & 1 & 0 & 0 & 0 & 1 \\
\hline FR bk & 0 & 54 & 5 & 2 & 0 & 6 & 0 & 2 & 16 & 11 & 1 & 2 & 4 & 6 & 3 & 5 \\
\hline DE bk & 3 & 9 & 78 & 3 & 2 & 3 & 1 & 4 & 11 & 7 & 2 & 4 & 11 & 8 & 10 & 10 \\
\hline IT bk & 3 & 5 & 1 & 83 & 17 & 16 & 4 & 0 & 1 & 0 & 5 & 0 & 2 & 2 & 3 & 0 \\
\hline NL bk & 1 & 2 & 0 & 5 & 61 & 1 & 1 & 3 & 3 & 3 & 3 & 7 & 19 & 4 & 9 & 4 \\
\hline ES bk & 2 & 23 & 3 & 1 & 1 & 56 & 1 & 10 & 4 & 3 & 1 & 1 & 1 & 1 & 1 & 4 \\
\hline PT bk & 2 & 1 & 0 & 1 & 0 & 1 & 84 & 0 & 0 & 1 & 2 & 0 & 1 & 1 & 2 & 1 \\
\hline DE & 4 & 1 & 1 & 0 & 2 & 2 & 0 & 70 & 13 & 8 & 2 & 10 & 4 & 5 & 3 & 6 \\
\hline BE & 0 & 2 & 0 & 0 & 1 & 1 & 1 & 1 & 34 & 0 & 1 & 3 & 1 & 2 & 2 & 5 \\
\hline FR & 1 & 2 & 0 & 0 & 1 & 2 & 1 & 0 & 5 & 61 & 1 & 1 & 1 & 3 & 1 & 1 \\
\hline GR & 0 & 0 & 0 & 0 & 1 & 0 & 0 & 1 & 0 & 0 & 76 & 0 & 1 & 0 & 0 & 1 \\
\hline NL & 1 & 0 & 0 & 1 & 1 & 2 & 0 & 2 & 9 & 3 & 1 & 68 & 1 & 2 & 1 & 7 \\
\hline ES & 1 & 0 & 6 & 2 & 8 & 8 & 1 & 1 & 0 & 1 & 0 & 1 & 50 & 7 & 15 & 1 \\
\hline IT & 0 & 0 & 0 & 0 & 1 & 1 & 0 & 1 & 1 & 1 & 2 & 1 & 2 & 58 & 3 & 2 \\
\hline PT & 0 & 0 & 0 & 0 & 0 & 0 & 1 & 0 & 1 & 0 & 2 & 1 & 2 & 1 & 40 & 0 \\
\hline IE & 1 & 0 & 0 & 1 & 0 & 0 & 3 & 1 & 0 & 1 & 0 & 0 & 1 & 1 & 8 & 53 \\
\hline
\end{tabular}

This table represents the average over time of the FEVDs obtained with the SVAR-GARCH. We can see that the originating shocks (in line) impact the most their own variables (in column).

number of historical events. In the spirit of Antolín-Díaz and Rubio-Ramírez (2018), we compare major shocks with historical economic and market events ${ }^{8}$. We define major shocks as those shocks that are higher than 6 times their own standard deviations. Of the 79 shocks that meet this criteria, we are able to match 62 events (covering $78 \%$ of major shocks) $)^{9}$. On Figure 2 we present the time series of the estimated structural shocks (in black) along with the timing of the matched events (red vertical lines). Figure 2 shows also isolated events of spillovers that fall short of the threshold for major events. Again, we are able to match a large amount of such shocks to economic and financial events, extending the list of events to 117 items. The identified events are typically rating downgrades or political shocks (for sovereigns) or bank stress episodes (for banking sectors). Annex A.3 reports the exhaustive list of events. This exercise suggests that our identification strategy based on major shock contribution is further supported by the event-analysis on structural shocks of Figure 2, something which is rarely performed in the SVAR literature.

\footnotetext{
${ }^{8}$ More precisely, for days with a large structural shock surge, we investigate the existence of major market events in the financial press.

${ }^{9}$ We consider that a peak is identified if we can match it with an event 5 days before or after the date of the peak. This ratio is robust to changes in the threshold value as well to changes in the number of days considered.
} 
Figure 2: Structural Shocks and Events
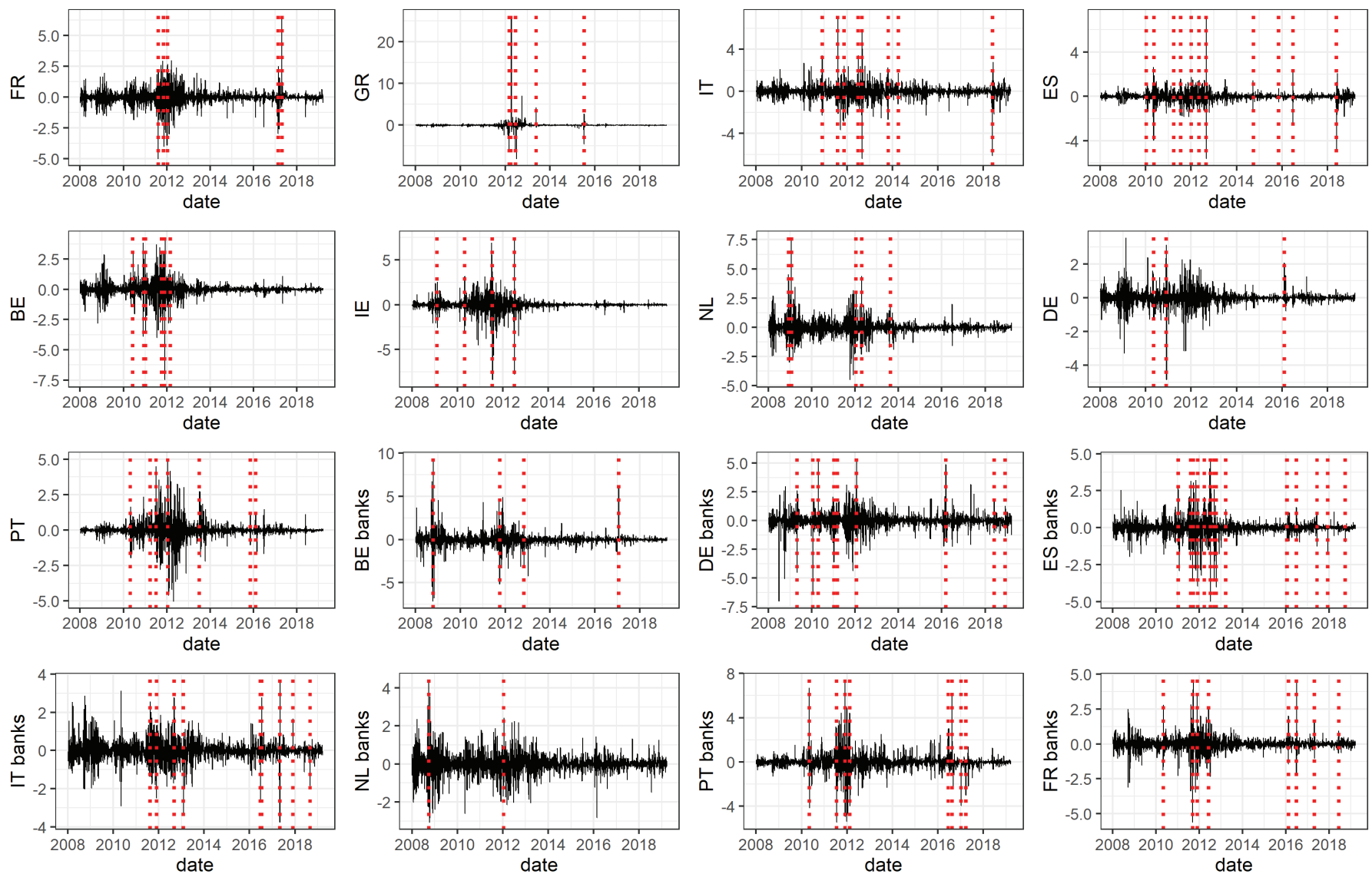

On the different graphs above are represented the estimated structural shocks of the model $\left(\hat{\boldsymbol{\epsilon}}_{t}\right)$ as well as identified historical events for each variable represented in vertical red lines. The list of events used is available in Annex A.3.

\subsubsection{Total Spillover Comparison}

How reactive is our model to new events? To assess its timeliness, we compare total spillovers ( $S^{H}$ in Equation 4) from our SVAR-GARCH model with total spillover estimates from other Diebold-Yilmaz approaches of the literature. More precisely, we estimate $S^{H}$ for the following 4 models $^{10}$ :

\footnotetext{
${ }^{10}$ Note that a comparison with the De Santis and Zimic (2018) model is unfeasible here as this latter does not yield daily estimates, due to heavy computation time, and cannot be compared with in a daily event-analysis.
} 
Model 1 A SVAR estimated on a rolling window and identified by Cholesky decomposition (as in Diebold and Yilmaz (2009), labeled here VAR Cholesky);

Model 2 A SVAR estimated on a rolling window and identified by GIRF/GFEVD (as in Diebold and Yilmaz (2012), labeled here VAR GIRF);

Model 3 A DCC-GARCH identified by Cholesky decomposition and estimated over the entire sample, labeled here DCC Cholesky. More precisely, we estimate a DCC GARCH as a reduced form VAR, that is:

$$
\boldsymbol{Y}_{t}=\boldsymbol{\beta}+\boldsymbol{A}_{1} \boldsymbol{Y}_{t-1}+\ldots+\boldsymbol{A}_{p} \boldsymbol{Y}_{t-p}+\boldsymbol{\mu}_{t}
$$

with:

$$
\boldsymbol{\mu}_{t} \sim N\left(\mathbf{0}, \boldsymbol{D}_{t} \boldsymbol{R}_{t} \boldsymbol{D}_{t}\right) \text { and } \boldsymbol{D}_{t} \boldsymbol{R}_{t} \boldsymbol{D}_{t}=\boldsymbol{H}_{t}
$$

following the notations of Engle (2002). We then switch to the structural form with a Cholesky decomposition at each period $t: \boldsymbol{B}_{0 t}^{-1} \boldsymbol{B}_{0 t}^{-1 \prime}=\boldsymbol{H}_{t}$;

Model 4 Similarly to Model 3, we estimate a VAR-GARCH based on a DCC-GARCH, but with the identification of Fengler and Herwartz (2018): $\boldsymbol{B}_{0 t}^{-1}=\boldsymbol{H}_{t}^{1 / 211}$. The model is labeled DCC Fengler.

Figure 3 plots the different $S^{H}$. First, the figure suggests that the SVAR-GARCH evaluates credit risk in the EZ to be significantly less integrated than VAR Cholesky and VAR GIRF. This may be linked to the fact that GIRF identification tends to overestimate total spillovers (as shown in De Santis and Zimic $(2018)^{12}$ ). In the same time, Cholesky

\footnotetext{
${ }^{11}$ Here, as in Fengler and Herwartz (2018), the square root of a symmetric positive definite matrix $\boldsymbol{H}$ is defined as $\boldsymbol{H}_{t}^{1 / 2}=\boldsymbol{\Gamma} \boldsymbol{\Lambda}^{1 / 2} \boldsymbol{\Gamma}^{\prime}$ where the columns of $\boldsymbol{\Gamma}$ contain the eigenvectors of $\boldsymbol{H}$ and $\boldsymbol{\Lambda}^{1 / 2}$ is diagonal with the positive square roots of the eigenvalues on its diagonal.

${ }^{12}$ As De Santis and Zimic (2018) show, when contemporaneous interaction effects between variables are not equal to 0 , the estimated standard errors of structural shocks obtained with GIRF are biased upwards, equally biasing upwards spillovers estimates based on FEVDs. The 0 restrictions the Cholesky identification introduces are likely to be at odds with the data generating process. In a numerical exercise De Santis and Zimic (2018) show that also this DY-model is likely to misspecify estimated spillovers.
} 
identification imposes restrictions that are likely to be at odds with the data generating process. SVAR models relying on this identification are thus susceptible to over- or underestimate total spillovers. We come back more formally on this point in Annex A.4.

Second, we see across all modelizations the 2010-2012 the "financial fragmentation" of the EZ. Indeed, each total spillover index is U-shaped: declining during those years, before increasing again afterwards. Ehrmann and Fratzscher (2017) and De Santis and Zimic (2018), who find similar shapes of total spillovers, argue that the latter decreased over 2010-2012 since shocks from peripheric countries had a decreasing impact on core countries.

Third, intuitively, indices relying on a rolling window estimation should be less responsive to new events compared to the SVAR-GARCH. However, there is no clear distinction $a$ priori in responsiveness between the different models with a GARCH-component.

This intuition is confirmed by a Granger causality analysis between the different $S^{H}$ given in Table 3. Indeed $S^{H}$ from the SVAR-GARCH does Granger cause $S^{H}$ indices from the rolling window estimated models (VAR GIRF and VAR Cholesky), but not the indices stemming from a DCC-GARCH (DCC Cholesky and DCC Fengler). When we reverse the perspective, SVAR-GARCH is only Granger caused by DCC Fengler and not by VAR Cholesky or VAR GIRF. In that sense, $S^{H}$ index estimated by DCC Fengler appears to be the most responsive to new events. However, as we show in the next section, the underlying pairwise spillovers estimated by DCC Fengler and DCC Cholesky are at odds with economic narratives. So that, contrary to the SVAR GARCH, these models fulfill the second condition of a good contagion model (responsiveness) but not the first one (good identification of the events). 
Figure 3: Total Spillover Indices from different Models

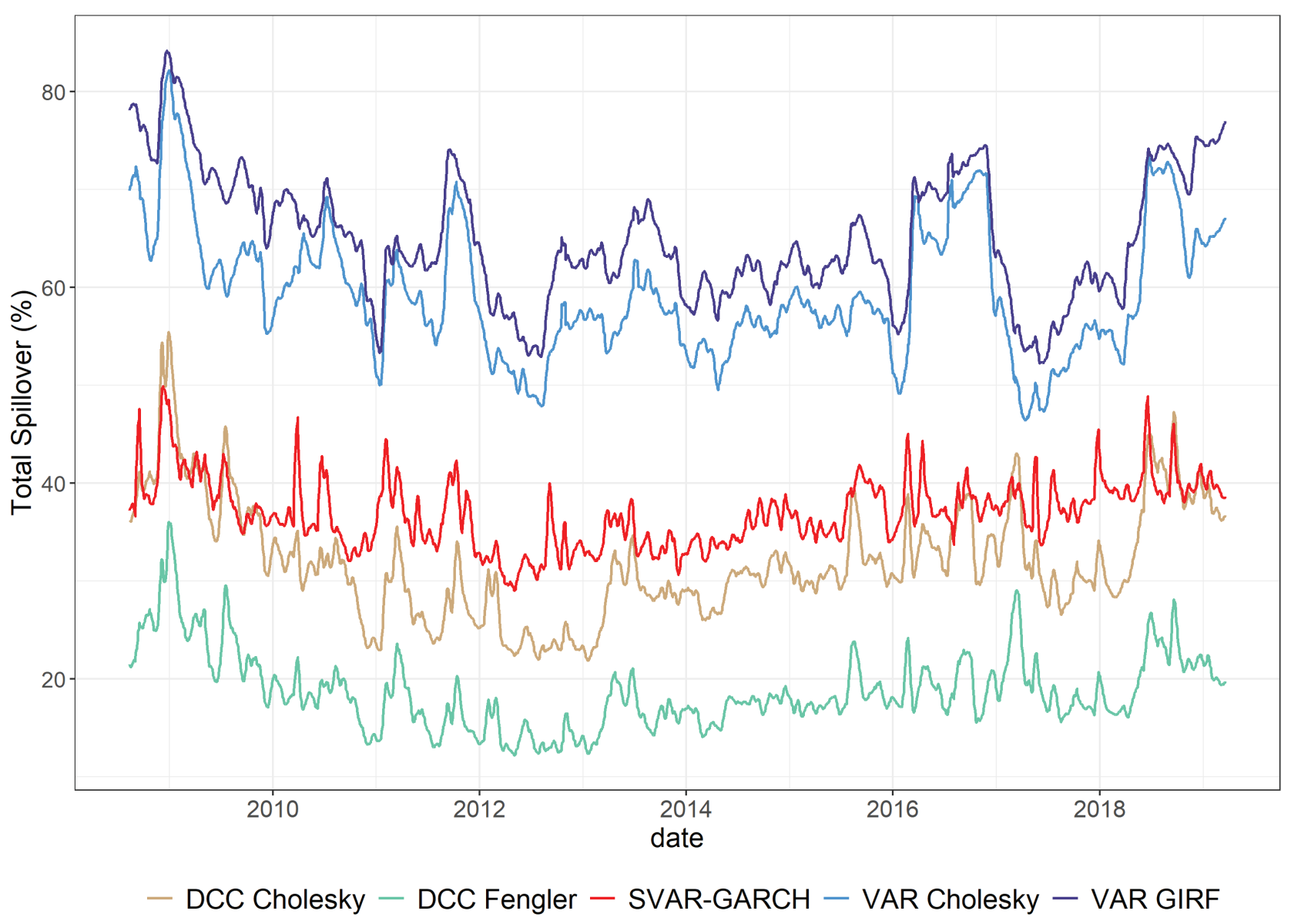

The different lines represent the Total Spillover indices $S^{H}$ built from the five different models outlined above. The rolling window models are estimated on a 100-day period, as standard in this strand of literature. For readability we show 10 day moving averages of the indices.

\subsubsection{Spillover Comparison and Narrative Events}

To evaluate the performance of our identification strategy compared to other models, we analyze how the different spillovers evolve along well-known narrative events.

To showcase our approach, we focus on the May 2018 political turmoil in Italy. At that time, the formation of a Eurosceptic coalition brought about a sharp increase in Italian 
Table 3: Granger causality between the models (First difference, lags=2)

\begin{tabular}{|c|c|c|}
\hline$H_{0}$ : SVAR-GARCH does not Granger cause... & F - test & p-value \\
\hline \multicolumn{3}{|l|}{ Rolling window estimated models } \\
\hline VAR Cholesky & 14.91 & $3.627 \mathrm{e}-07^{* * *}$ \\
\hline VAR GIRF & 6.0492 & $0.002391 * *$ \\
\hline \multicolumn{3}{|l|}{ GARCH-related models } \\
\hline DCC Cholesky & 1.0527 & 0.3491 \\
\hline DCC Fengler & 1.3641 & 0.2558 \\
\hline$H_{0}$ : SVAR-GARCH is not Granger caused by... & F - test & p-value \\
\hline \multicolumn{3}{|l|}{ Rolling window estimated models } \\
\hline VAR Cholesky & 0.5159 & 0.597 \\
\hline VAR GIRF & 0.9483 & 0.3875 \\
\hline \multicolumn{3}{|l|}{ GARCH-related models } \\
\hline DCC Cholesky & 0.4206 & 0.6567 \\
\hline DCC Fengler & 8.8071 & $0.0001539^{* * *}$ \\
\hline
\end{tabular}

This table indicates the results from the Granger causality tests between the $S^{H}$ of the different models. Only three Granger causality relationships appear significant: SVAR-GARCH on VAR Cholesky and VAR GIRF, and DCC Fengler on SVAR-GARCH. The marks *, **, *** indicate, respectively, the following significance levels: $0.1,0.05$ and 0.01

sovereign $\mathrm{CDS}^{13}$. We argue that this event should be interpreted as sovereign shock, not as a bank shock. In that regard, one would expect an increase in outward spillovers $\left(S_{j \rightarrow \bullet}^{H}\right.$ of Equation 3) from the Italian sovereign at the time of the events. Yet, the upper part of Figure 4 shows that only the spillover estimates from the SVAR-GARCH do so during this period (highlighted in red), while other methodologies' spillovers remain subdued.

Moreover, as CDS spreads tend to comove a lot (Longstaff et al. (2011)), especially

\footnotetext{
${ }^{13}$ see https://www.ft.com/content/eed97b90-6306-11e8-90c2-9563a0613e56, or Reuters https://www.reuters.com/article/us-eurozone-bonds/italian-bonds-suffer-worst-day-in-more-than25-years-idUSKCN1IU16G
} 
Figure 4: Outward Spillovers from Italian sovereign and bank shocks
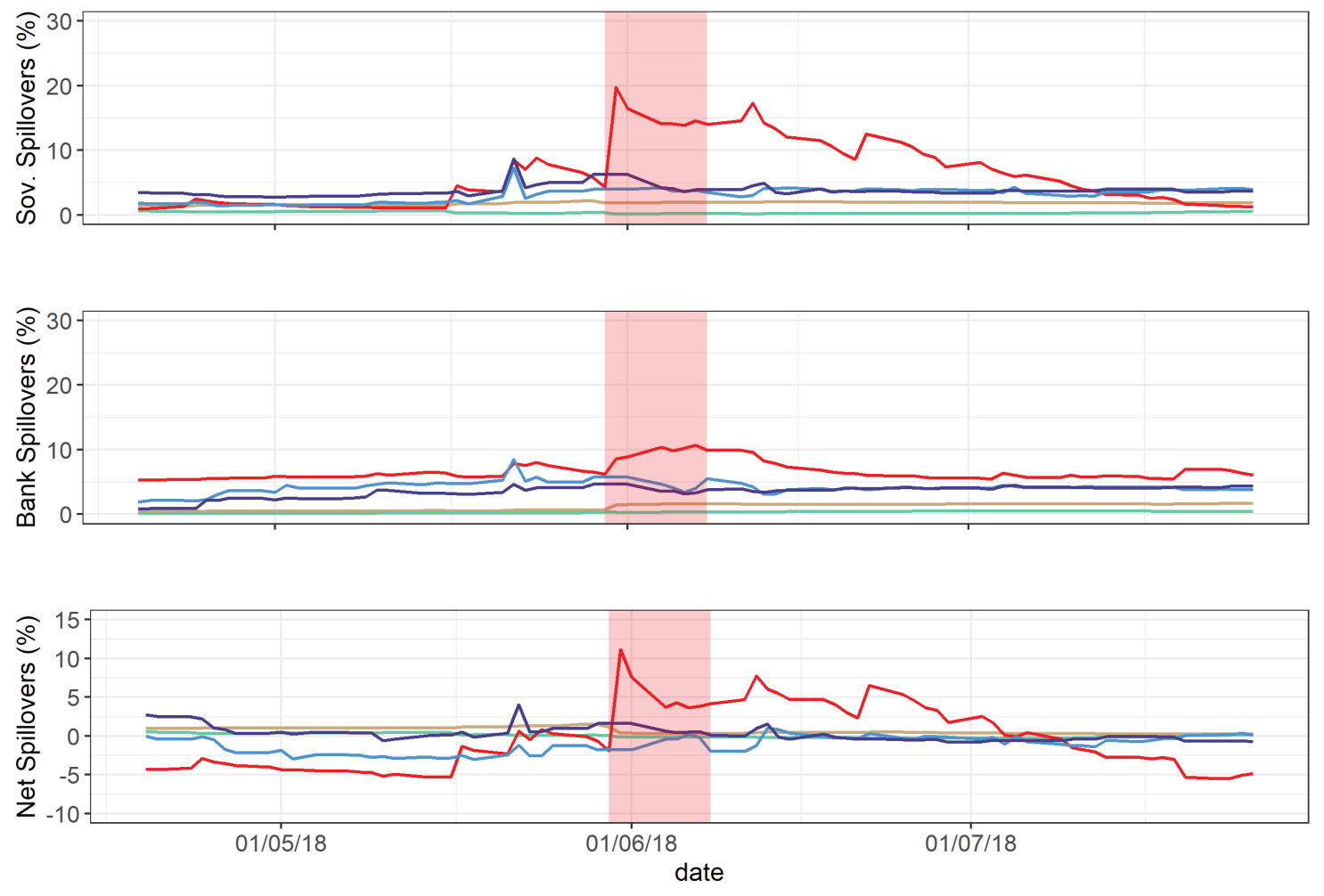

- DCC Cholesky - DCC Fengler - SVAR-GARCH - VAR Cholesky - VAR GIRF

The two upper parts of the graph represent the Outward Spillover Index $\left(S_{j \rightarrow \bullet}^{H}\right)$ from, respectively, the Italian sovereign and the Italian banks, built from the five different models outlined above. The bottom part of the graph represents the "net" spillovers (outward sovereign spillovers minus outward bank spillovers). The periods highlighted in red represent the May 2018 Italian political turmoil.

between sovereign and bank CDS series from the same country, there is a high risk that a model confuses bank shocks with their corresponding sovereign shocks. Accordingly, at the time of a sovereign event, outward spillovers from the country's banking sector should remain flat or decrease. Therefore, for a sovereign event to be correctly identified, not only the sovereign spillovers should increase, they should also increase by more than the corresponding bank spillovers. On the middle and lower parts of Figure 4 we display the outward spillovers from Italian banks as well as the difference between sovereign and bank outward spillovers ("net" spillovers). While most of the models exhibit flat 
or negative net spillovers, only the SVAR-GARCH manages well to identify this specific event on this measure.

To evaluate on a more systematic basis the identification strategies of the different models, we replicate the analysis of Figure 4 over the set of our identified events available in Annex A.3. We estimate that a sovereign (bank) event is well identified if, 5 days around the day of the event, the spillover estimate stemming from the sovereign (banking sector) increases more than the spillover estimate from the banking sector (sovereign) in the same country. We evaluate the identification performance of the models on different sets of events: (i) a subset of the least contestable sovereign events (i.e. only elections, sovereign rating downgrades, or political events) of the list identified in Section 5.1.1 and shown in Annex A.3 covering 18 events, (ii) all sovereign events in Annex A.3 covering 54 events and (iii) all events, bank and sovereign, in Annex A.3 covering 117 events. As the sets of events (i), (ii) and (iii) are generated from our model, we corroborate the analysis with two exogenous lists of sovereign events, from (iv) Candelon et al. (2011) which covers 11 events and (v) Alexandre et al. (2016) that includes 8 events.

Table 4 suggests that the SVAR-GARCH outperforms, on every set of events, the other models in terms of identification. Note also that the competing models barely exceed the $50 \%$ threshold of identification, meaning that they tend to confuse more sovereign events with banking events than a random selection ${ }^{14}$.

\footnotetext{
${ }^{14}$ Results reported in Table 4 are robust to a large number of specifications (by analysing the $\%$ change instead of absolute changes, with different window lengths or with pairwise spillovers instead of outward spillovers).
} 
Table 4: Percentage of good event-identification by model

\begin{tabular}{c|c|c|c|c|c} 
& $\begin{array}{c}\text { DCC } \\
\text { Fengler }\end{array}$ & $\begin{array}{c}\text { DCC } \\
\text { Cholesky }\end{array}$ & $\begin{array}{c}\text { VAR } \\
\text { GIRF }\end{array}$ & $\begin{array}{c}\text { VAR } \\
\text { Cholesky }\end{array}$ & $\begin{array}{c}\text { SVAR - } \\
\text { GARCH }\end{array}$ \\
\hline $\begin{array}{c}\text { (i) Subset of sovereign } \\
\text { events }\end{array}$ & 11.0 & 22.0 & 44.0 & 39.0 & $\mathbf{7 8 . 0}$ \\
\hline $\begin{array}{c}\text { (ii) Total sovereign } \\
\text { events }\end{array}$ & 30.8 & 33.3 & 33.3 & 38.5 & $\mathbf{6 4 . 1}$ \\
\hline $\begin{array}{c}\text { (iii) Total sovereign } \\
\text { and bank events }\end{array}$ & 34.2 & 36.8 & 39.5 & 47.4 & $\mathbf{6 8 . 4}$ \\
\hline $\begin{array}{c}\text { (iv) Candelon et al. } \\
(2011)\end{array}$ & 36.3 & 45.4 & 36.4 & 44.6 & $\mathbf{6 3 . 6}$ \\
\hline $\begin{array}{c}\text { (v) Alexandre et al. } \\
(2016)\end{array}$ & 12.5 & 25.0 & 75.0 & 0.5 & $\mathbf{7 5 . 0}$
\end{tabular}

Note: This table reports the percentage of correct event identifications by each model. E.g. we consider a sovereign event to be correctly identified if, 5 days around the event, the outward spillover stemming from the sovereign increases more than the outward spillover stemming from the corresponding banking sector. The results are reported for (i) uncontroversial sovereign events (sovereign rating downgrades and votes) (ii) all the sovereign events previously identified (iii) all the sovereign and banking events identified (iv) the sovereign event list of Candelon et al. (2011) (v) the sovereign event list of Alexandre et al. (2016).

\subsection{Economic results}

Figure 3 on total spillover indices shows that we estimate credit risk to be less integrated than other models would suggest. According to our $S^{H}$ estimates, on average about $37 \%$ of the variation in the filtered CDS rates can be explained by spillovers. Yet, we find substantial variation in this magnitude over time. To investigate the sources of heightened spillovers, this section analyses first the time-variation of both bank and sovereign spillovers from the EZ countries, and then the economic channels behind the spillovers we estimate. As our estimates match both the narrative of spillovers in the EZ debt crisis (Section 5.2.1) and the theoretical channels of credit risk spillovers (Section 5.2.2), we interpret these economic results as a further validation of our identification strategy. 


\subsubsection{Group pairwise spillovers}

In this section, we analyse credit risk spillovers in terms of (i) timing, (ii) magnitude and (iii) origin. Given, that we estimate spillovers between 16 CDS series, presenting the resulting 240 pairwise spillovers is not feasible. We focus therefore on pairwise spillovers from different sets of countries/banking sectors. In the "Peripheric" group are included the high-debt countries at the time of the EZ debt crisis: Italy, Spain, Portugal, Greece, Belgium and Ireland ${ }^{15}$. The "Core" group, on the reverse, is constituted by Germany, France and the Netherlands. The "Peripheric banks" and "Core banks" include the corresponding banking sectors. However, as indicated in Section 4, due to data-constraints the group "Peripheric banks" does not include Greek and Irish banking sectors.

Figure 5 presents estimates of group pairwise spillovers for each variable sets defined above. In line with Section 3.1 we define the group pairwise spillover from group $G_{1}$ to group $G_{2}$ as the average outward spillovers from $G 1$ restricted to the variables of $G_{2}$. More formally we have:

$$
S_{G_{1} \rightarrow G_{2}}^{H}=\frac{1}{N_{G_{1}} N_{G_{2}}-N_{G_{1}} \mathbb{1}_{\left\{G_{1}=G_{2}\right\}}} \sum_{i \in G_{1}} \sum_{\substack{j \in G_{2} \\ j \neq i}} d_{i j}^{H}
$$

With $N_{G_{1}}$ and $N_{G_{2}}$ the number of variables in $G_{1}$ and $G_{2}{ }^{16}$. Each line represents by how much shocks from a variable set drive the variation of other variable sets on average. The analysis of time-varying spillovers here differs from the presentation of snapshots spillovers around narrative events in Section 5.1.3 (as we focus here on a much broader time period) and also from the presentation of the shocks in Section

\footnotetext{
${ }^{15}$ Note that we include Belgium in the Periphery-group as the country exhibited high public debt/GDP ratio. However the results are very similar if we define Belgium as a Core country.

${ }^{16}$ Contrary to Equations 2 and 3, we divide here the index by the number of pairwise directed spillovers considered. Likewise the different indices of Figure 5 are expressed in the same unit, that is: by how much, on average, a single variable of $G_{1}$ has an impact on a single different variable of $G_{2}$.
} 
5.1.1. This is because spillover estimates in our DY-framework are not only functions of the time-varying variances of structural shocks $\left(\boldsymbol{\lambda}_{t}\right)$, but also of the interaction matrix $\left(\boldsymbol{B}_{0}\right)$ and of the VAR coefficients $\left(\boldsymbol{A}_{i}\right)$. Therefore a large structural shock does not necessarily translate into a large spillover if it is associated with low coefficients in the corresponding matrices or if the magnitude of the shock is low relatively to other shocks' variances.

Figure 5 can be read in two ways, either from a shock to perspective by rows, or from a shock from perspective by columns. In the following, we take the shock to perspective. Figure 5 shows significant variation across time and groups. We find, in line with conventional wisdom, sizeable effects of sovereign periphery shocks to the rest of the EZ clustered around the beginning of the debt crisis in 2010. For example, at the height of the EZ debt crisis around mid-December 2010 when Moody's put Spain's rating on review, single variables from periphery sovereign shocks explained on average $4 \%$ and $3.5 \%$ of the variation of single variables from periphery sovereign and periphery banking groups respectively. Other major events of spillovers from periphery sovereigns include the Irish request for financial support to the EU's Financial Stability Facility and the IMF, the EU finance minister gathering to decide Greece's fate in 2015 or the 2018 Italian election crisis amid fears of new elections and voter support for Eurosceptics (see the subcaption of Figure 5 for exact dates). Figure 5 suggests that periphery sovereign shocks affect strongest CDS rates in other sovereign periphery countries followed by periphery banking sectors. Yet, core sovereigns and banks were also significantly affected periphery sovereign shocks.

We also find sizable spillovers from the periphery banking sector to other blocks in the EZ. For example, Figure 5 shows elevated spillovers at the beginning of 2013, when investors worried about the health of the Italian banking sector (due to high NPL ratios amid excessive reliance on debt), as well as at the beginning of 2016, when again concerns 
about NPLs and the lack of credibility in the Italian banking sector heightened. We also find increased spillovers around dates between 2011 and mid-2012 when the Spanish banking sector signaled problems.

While we find spillovers from periphery EZ countries to increase with the beginning of the Euro debt crisis, we find spillovers from core EZ countries to be stronger during 2008/09 financial crisis. As such, we estimate strong sovereign core spillovers in January 2009 when the Dutch government announced plans to provide a backup facility to cover the risks of the ING's securitised mortgage portfolio. Moreover, Figure 5 shows increased sovereign core spillovers around dates that coincide with a downgrade of France by SP as well as the second round presidential election stand-off between Emmanuel Macron and Marine Le Pen. Finally, we find strong core bank spillovers, for example around the dates when ING received 10bn EUR from the Dutch government or when BNP entered a liquidity crunch when the bank was no longer able to borrow in USD. Overall, compared to their periphery counterparts, we find sudden increases of spillovers from core countries to be less frequent.

\subsubsection{What economic channels explain spillovers?}

While in the previous section we discussed the sources and time-variation of outward and total spillovers, this section focuses on the economic channels underlying the pairwise spillovers we estimate. More specifically, given a shock to a sovereign or banking sector in our sample, we vet whether the resulting pairwise spillovers match the economic channels proposed by the theoretic and empirical literature as an additional test for our identification strategy. We focus here on four different types of spillovers: (i) international sovereign to sovereign spillovers, (ii) international bank to bank spillovers, (iii) national bank to sovereign spillovers and finally (iv) national sovereign to bank spillovers. 
Figure 5: Outward spillovers from peripheric EZ countries (\%)
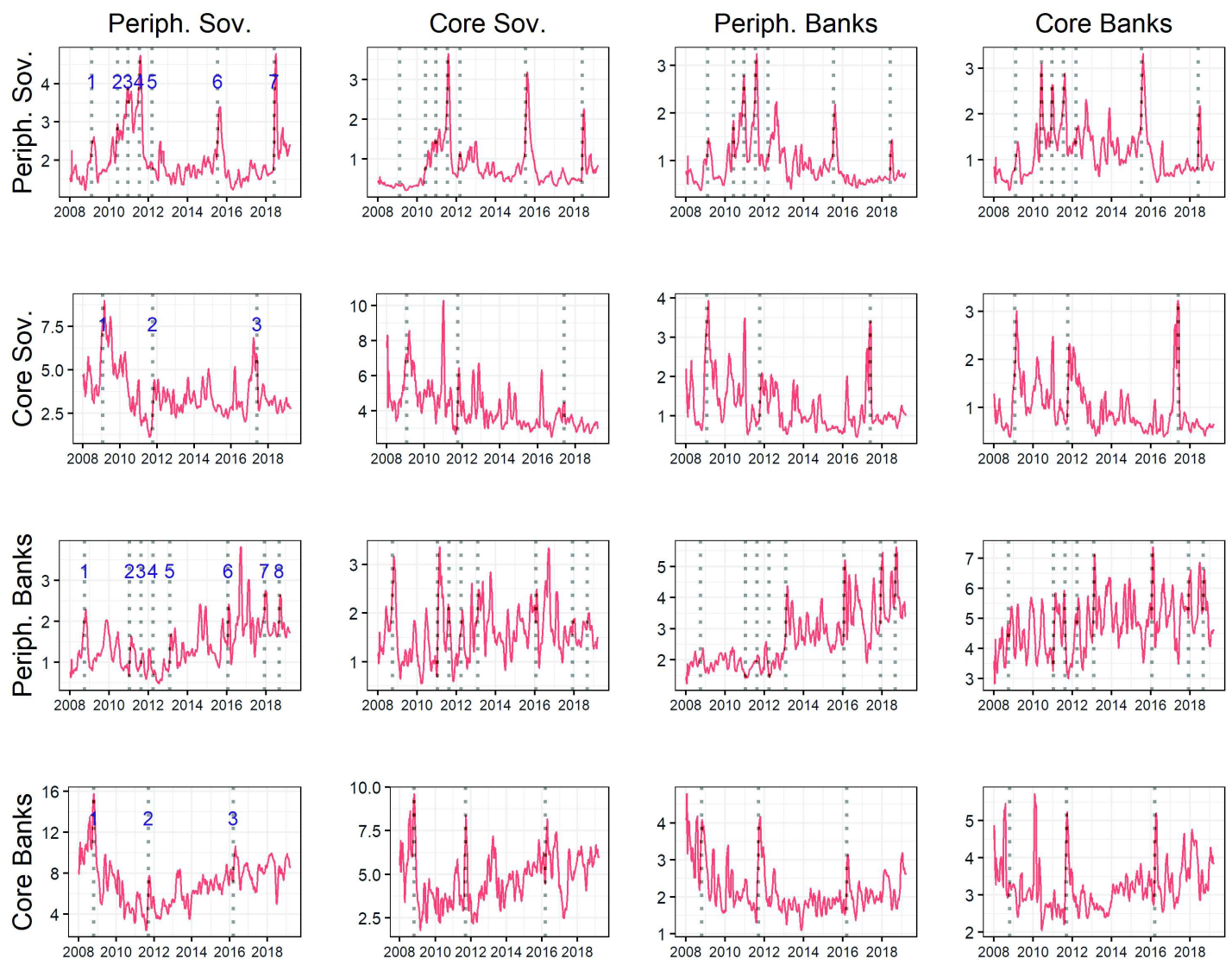

The different lines represent group pairwise spillovers $\left(S_{G_{1} \rightarrow G_{2}}^{H}\right)$ for the 4 groups: Peripheric sovereigns, Core Sovereigns, Peripheric banks, Core banks. For readability we show 30 day moving averages of the indices. Peripheric Sovereigns: 1) Ireland recapitalizes its two main banks 11/02/09, 2) Belgium struggles to raise debt among political uncertainty 07/06/10, 3) Moody's puts Spain's ratings on review 15/12/10, 4) Market pressure on Spanish and Italian sovereigns 17/07/11, 5) ISDA declares Greece in default 09/03/12, 6) EU finance minister gathering to decide Greece's fate 11/07/15, 7) Italy election crisis spreads as $C B$ chief warns about investor trust 30/05/18, Core Sovereigns: 1) Dutch government announces plans to rescue banks 26/01/09, 2) SP mistakenly downgrades France 10/11/11, 3) French elections, spike in sovereign CDS 24/05/17, Peripheric Banks: 1) Dexia bailed out 30/09/08, 2) Concerns on Spanish banks 14/01/11, 3) Trading suspension for Italian bank IS 17/08/11, 4) Need for Spanish bailout is underlined by EU officials 28/03/12, 5) MPS asks for 3.9bn bailout 01/02/13, 6) Market sentiment turns against Spain's banking sector 21/01/16, 7) ECB undernlines Italian banks' NPL problems 29/11/17, 8) UniCredit and IS fall on news of increased political uncertainty 31/08/18 Core Banks: 1) ING receives 10 bn from Dutch government 19/10/08, 2) BNP can no longer borrow USD 13/09/11, 3) Deutsche and UBS defeated in UK tax avoidance case 10/03/16. 


\section{International spillovers}

First, we address the following question: given a sovereign shock in country $i$, what factors are the international spillovers to the sovereign risk in country $j$ associated with? We follow broadly the regression approach by De Santis and Zimic (2018) and regress the credit risk spillover of sovereign $i$ on sovereign $j$ in quarter $t$ on a set of regressors that can be divided into two main groups: distance and exposure. We estimate:

$$
\bar{\omega}_{i \rightarrow j, t}(h)=\beta_{i}+\alpha_{t}+\beta_{2} d_{i j, t}^{G D P}+\beta_{3} d_{i j, t}^{\frac{D}{G D P}}+\beta_{4} \operatorname{exposure}_{j \rightarrow i, t}^{k}+\epsilon_{i j, t}
$$

where $\bar{\omega}_{i \rightarrow j, t}(h)$ is the average spillover from $i$ to $j$ at forecast horizon $h$ over the quarter $t$, all variables $d$ are distance measures that include (i) the squared difference between country $i$ and country $j$ 's GDP growth in $t$ and (ii) the squared difference between country $i$ and country $j$ 's government debt to GDP ratio in $t^{17}$. Exposure $\operatorname{Expi,t}_{j \rightarrow \text { is }}$ the exposure of country $j$ to country $i$ in respect of either the share of exports or portfolio assets (equity and bonds). The choice of those exposure variables follows the empirical work by De Santis and Zimic (2018) and the theoretical work by Foerster et al. (2011), see Annex A.5 for data sources and construction of the explanatory variables. We use time fixed effects and, following De Santis and Zimic (2018), fixed effects for the origin of the sovereign shock.

The results, reported in Table 5 suggest that similarity in business cycles cannot explain spillovers in sovereign risk. Instead, we find that similar credit risk in terms of similar debt to GDP ratios as well as both stronger trade and portfolio exposure are significantly related to higher sovereign risk spillovers. This finding supports the business cycle network literature (such as Foerster et al. (2011)) which models contagion channels through exactly those two exposure variables ${ }^{18}$.

\footnotetext{
${ }^{17}$ We multiply difference variables by -1 , such that the indicators increase in similarity.

${ }^{18}$ As the use of generated dependent variables in the regression can induce heteroskedasticity (see De
} 
Table 5: Factors associated with spillovers from sovereigns to sovereigns

\begin{tabular}{lccc}
\hline \hline & $(1)$ & $(2)$ & $(3)$ \\
\hline Similar BC & -0.00005 & -0.002 & -0.001 \\
& $(0.001)$ & $(0.001)$ & $(0.001)$ \\
Similar D/GDP & $0.021^{* * *}$ & $0.007^{* * *}$ & $0.014^{* * *}$ \\
& $(0.002)$ & $(0.002)$ & $(0.002)$ \\
Trade exposure & & $0.433^{* * *}$ & \\
& & $(0.020)$ & \\
Investment exposure & & & $0.236^{* * *}$ \\
& & & $(0.028)$ \\
\hline Time fixed effects? & Yes & Yes & Yes \\
i fixed effects? & Yes & Yes & Yes \\
Observations & 3,240 & 3,240 & 3,171 \\
$\mathrm{R}^{2}$ & 0.448 & 0.598 & 0.490 \\
Adjusted $\mathrm{R}^{2}$ & 0.438 & 0.591 & 0.481 \\
\hline \hline
\end{tabular}

We repeat the same exercise to investigate the determinants of a spillover from the banking sector in country $i$ to the banking sector in country $j$. Similar to Equation 26, we regress pairwise banking spillovers on a fixed effect for the shocking banking sector, as well as distance and exposure variables.

$$
\bar{\omega}_{i \rightarrow j, t}(h)=\beta_{i}+\alpha_{t}+\beta_{2} d_{i j, t}^{N P L}+\beta_{3} d_{i j, t}^{L e v . R .}+\beta_{4} \operatorname{exposure}_{j \rightarrow i, t}^{k}+\epsilon_{i j, t}
$$

The distance variables include credit risk distances which we estimate by the squared difference between country $i$ and country $j$ 's banking sector's non-performing loans and capital ratios in period $t^{19}$. In terms of exposures we test for two economic channels that are frequently used to model financial institution linkages: cross asset holdings and similarities in portfolios across banking sectors (see Giudici et al. (2020), Brunetti et al. (2019), Greenwood et al. (2015)). We construct bank sector portfolios from BIS Santis and Zimic (2018)), we report White heteroskedasticity-consistent standard errors.

${ }^{19}$ Here again, we multiply difference variables by -1 , such that the indicators increase in similarity. 
Consolidated Banking Statistics data, following Greenwood et al. (2015), and calculate squared differences of those portfolios for each time period $t$. Cross asset holdings between banking systems are measured as the share of banks claims of country $j$ vis-à-vis country $i$.

The results, shown in Table 6, suggest that cross-asset holdings are not significantly linked to the bank to bank spillovers. We do find however, that portfolio similarities are significantly associated with bank to bank spillovers. Both these findings are in line with the literature (Brunetti et al. (2019)). Similarly to the sovereign regressions, risk distances have some explicative power: we find that international bank spillovers are significantly associated with similar capital ratios for pairs of banking systems. However, similar NPL ratios turn out not to be of statistical significance.

Table 6: Factors associated with spillovers from banks to banks

\begin{tabular}{lccc}
\hline \hline & $(1)$ & $(2)$ & $(3)$ \\
\hline Similar NPLs & -0.001 & -0.003 & -0.001 \\
& $(0.003)$ & $(0.003)$ & $(0.003)$ \\
Sim. Capital ratios & $0.037^{* * *}$ & $0.029^{* *}$ & $0.040^{* * *}$ \\
& $(0.009)$ & $(0.010)$ & $(0.010)$ \\
Similar portfolio & & $7.304^{* * *}$ & \\
& & $(1.355)$ & \\
Bank claims & & & -0.013 \\
& & & $(0.009)$ \\
\hline Time fixed effects? & Yes & Yes & Yes \\
i fixed effects? & Yes & Yes & Yes \\
Observations & 1,812 & 1,812 & 1,812 \\
$\mathrm{R}^{2}$ & 0.434 & 0.439 & 0.435 \\
Adjusted R ${ }^{2}$ & 0.417 & 0.422 & 0.417 \\
\hline \hline & ${ }^{*} \mathrm{p}<0.05 ;{ }^{* *} \mathrm{p}<0.01 ;{ }^{* * *} \mathrm{p}<0.001$
\end{tabular}

Spillovers in the national sovereign - bank nexus

While in the previous two regression sets we have focused on international spillovers, we investigate in the next two regressions the economic determinants of the national 
sovereign bank-nexus. In this section, we differentiate between high debt (Belgium, Italy, Portugal and Spain) and low debt (France, Germany and the Netherlands) countries as in the European debt crisis periphery and core countries experienced substantially different degrees of sovereign-bank nexuses (Podstawski and Velinov (2018)).

We focus first on the economic transmission channels of domestic spillovers from banks to sovereigns. First, one reason for higher spillovers may simply be a more vulnerable economy. We include in the regression measures of debt to GDP ratios, current account and GDP growth as predictor variables. Second, bank risk may also affect domestic sovereign risk through the "bailout channel", that is explicit or implicit public guarantees, in case of distress of the banking sector (Alter and Schüler (2012)). To proxy this effect, we add as a predictor the capital ratio of the banking sector. Intuitively, the bailout channel should be significant if domestic banks are undercapitalized and in potential need of public support. Third, another potential channel of spillovers is that when a banking sector is in distress, it can trigger fire sales of the government bonds it holds, increasing in turn the credit risk of the sovereign issuer. Fourth, distress for banks may affect their lending activity and therefore impact sovereign risk through a slowdown in economic growth (Podstawski and Velinov (2018)). For the third and fourth channels, we therefore include two exposure variables in the regression set: the share of domestic government bonds and the share of domestic non-bank assets that the banking sector holds. Denoting $v_{s}^{k}$ the vulnerability variable $k$ for sector $s$, Equation 27 restates the OLS regressions we estimate:

$$
\begin{array}{r}
\bar{\omega}_{\text {bank }_{i} \rightarrow \operatorname{sov}_{i}, t}(h)=\beta_{0}+\alpha_{t}+\beta_{1} v_{\text {bank }_{i}, t}^{\text {Lev }_{2}}+\beta_{2} v_{\text {sov }_{i}, t}^{D / G D P}+\beta_{3} v_{\text {sov }_{i}, t}^{C A}+\beta_{4} v_{\text {sov }_{i}, t}^{g_{G D P}} \\
+\beta_{5} \operatorname{exposure}_{\text {sov }_{i} \rightarrow \text { bank }_{i}, t}^{k}+\epsilon_{\text {bank }_{i}, \text { sov }_{i}, t}
\end{array}
$$

Note that for the vulnerability variables, we use dummies instead of continuous variables 
contrary to Equations 25 and $26^{20}$. We define high and low realisations of the variables with regards to their overall sample mean ${ }^{21}$. Since the sample is split according to debt levels, using the mean debt/GDP as threshold for the construction of a debt dummy does not yield much variation in the high debt subsamples. We therefore use the subsample mean for the high debt country group, and the overall sample mean for the low debt country group ${ }^{22}$.

We find in Table 7 that low capital ratios and high debt to GDP ratios are significantly associated with stronger domestic spillovers from banks to sovereigns. This suggests that the "bailout channel" may indeed be important in explaining the sovereign-bank nexus (Fratzscher and Rieth (2019)), as is higher sovereign indebtedness. Moreover, we find that neither the capital account nor GDP growth is significantly associated with the spillovers we estimate. While the vulnerability variables yield similar results concerning the significance of the indicators across country groups, the results for the exposure variables differ. For high debt countries, both the dependence of the domestic non-bank corporate sector and government on domestic bank lending are not significant. In contrast, we find for low debt countries that higher non-bank exposure to domestic lending is significantly associated with higher domestic bank to sovereign spillover, suggesting that reduced lending activity in the case of a banking shock may indeed feed through the corporate sector into sovereign risk (see Pagano (2018)). As for high debt countries, we also find non-significant effects of sovereign debt exposure to domestic bank for low

\footnotetext{
${ }^{20}$ The underlying reason for using continuous variables for Equations 25 and 26 is that investors on the CDS markets may pass the shock of one sovereign (bank) to the price of another sovereign (bank) CDS if they judge them as similar. However for bank-to-sovereign or sovereign-to-bank regressions we cannot rely on such similarity metrics as the giving and the receiving variables are of different types. Therefore for Equations 27 and 28 we consider that investors pass the shock of a bank (sovereign) to a sovereign (bank) CDS if they judge the receiving variable as not resilient enough. This kind of reasoning is discrete, therefore we turn to dummy variable so as to illustrate the threshold that investors may consider.

${ }^{21}$ Defined by $15.2 \%$ for the capital ratio, $0.5 \%$ for the capital account and $0.3 \%$ for real GDP growth.

${ }^{22}$ We use the overall sample mean $(86.5 \%)$ for the low debt group, and not the subsample mean $(70 \%)$ as crossing the latter is unlikely to appear as warning signal for investors. Indeed, Germany has crossed this threshold between 2009 and 2016 while keeping its status as safe heaven. The subsample mean is at $101.7 \%$ for the high debt group
} 
debt countries.

Table 7: Factors associated with spillovers from banks to sovereigns in same country

\begin{tabular}{|c|c|c|c|c|c|c|}
\hline & \multicolumn{3}{|c|}{ High debt countries } & \multicolumn{3}{|c|}{ Low debt countries } \\
\hline & $(1)$ & $(2)$ & $(3)$ & $(4)$ & $(5)$ & $(6)$ \\
\hline Capital & $\begin{array}{c}-0.91^{* * *} \\
(0.21)\end{array}$ & $\begin{array}{c}-0.91^{* * *} \\
(0.21)\end{array}$ & $\begin{array}{c}-1.01^{* *} \\
(0.31)\end{array}$ & $\begin{array}{c}-5.01^{* * *} \\
(1.04)\end{array}$ & $\begin{array}{c}-5.07^{* * *} \\
(1.05)\end{array}$ & $\begin{array}{c}-3.88^{* * *} \\
(1.07)\end{array}$ \\
\hline Debt to GDP & $\begin{array}{c}1.00^{* * *} \\
(0.17)\end{array}$ & $\begin{array}{c}1.01^{* * *} \\
(0.17)\end{array}$ & $\begin{array}{c}0.88^{* * *} \\
(0.21)\end{array}$ & $\begin{array}{l}3.74^{* *} \\
(1.29)\end{array}$ & $\begin{array}{l}3.56^{* *} \\
(1.28)\end{array}$ & $\begin{array}{l}3.50^{* *} \\
(1.22)\end{array}$ \\
\hline Current Account & $\begin{array}{c}0.13 \\
(0.20)\end{array}$ & $\begin{array}{c}0.13 \\
(0.26)\end{array}$ & $\begin{array}{c}0.23 \\
(0.28)\end{array}$ & $\begin{array}{l}-0.63 \\
(1.26)\end{array}$ & $\begin{array}{c}-0.62 \\
(1.28)\end{array}$ & $\begin{array}{c}0.16 \\
(1.31)\end{array}$ \\
\hline GDP growth & $\begin{array}{l}-0.06 \\
(0.22)\end{array}$ & $\begin{array}{l}-0.05 \\
(0.23)\end{array}$ & $\begin{array}{l}-0.05 \\
(0.22)\end{array}$ & $\begin{array}{l}-0.29 \\
(0.66)\end{array}$ & $\begin{array}{l}-0.31 \\
(0.66)\end{array}$ & $\begin{array}{l}-0.28 \\
(0.68)\end{array}$ \\
\hline Sov. exposure & & $\begin{array}{c}0.06 \\
(1.92)\end{array}$ & & & $\begin{array}{c}2.94 \\
(9.63)\end{array}$ & \\
\hline Non-bank exposure & & & $\begin{array}{l}-0.88 \\
(1.50) \\
\end{array}$ & & & $\begin{array}{c}20.52^{* * *} \\
(6.02) \\
\end{array}$ \\
\hline Time fixed effects? & Yes & Yes & Yes & Yes & Yes & Yes \\
\hline Observations & 174 & 174 & 174 & 123 & 123 & 123 \\
\hline $\mathrm{R}^{2}$ & 0.74 & 0.74 & 0.74 & 0.93 & 0.93 & 0.94 \\
\hline Adjusted $\mathrm{R}^{2}$ & 0.64 & 0.64 & 0.64 & 0.89 & 0.89 & 0.90 \\
\hline
\end{tabular}

Finally, we investigate the determinants of domestic credit risk spillovers from a country's sovereign to its banking sector (see Equation 28). We test the following hypotheses: First, are domestic spillovers to banks stronger if the banking sector is more vulnerable? We proxy here bank vulnerability with capital ratio, liquidity (measured by liquid assets to short term liabilities) and NPL ratios. Second, are spillovers stronger if the domestic banking sector holds more domestic government debt, expressed in $\%$ of total assets (the "balance sheet channel" as described in Angeloni and Wolff (2012) and Buch et al. (2016))? Third, are spillovers stronger if the domestic banking sector holds more assets of domestic non-financial firms, expressed in \% of total assets (the "real economy channel" $\left.{ }^{23}\right)$ ? Here again, we express vulnerability variables in terms of dummies, where

\footnotetext{
${ }^{23}$ The underlying rationale for this hypothesis is that a sovereign shock can feed into the real sector
} 
the thresholds between high and low realisations are set to sample averages ${ }^{24}$. We estimate:

$$
\begin{aligned}
\bar{\omega}_{\text {sov }_{i} \rightarrow \text { bank }_{i}, t}(h)=\beta_{0}+\alpha_{t} & +\beta_{1} v_{\text {bank }_{i}, t}^{N P L}+\beta_{2} v_{\text {bank }_{i}, t}^{\text {Lev }_{i},}+\beta_{3} v_{\text {bank }_{i}, t}^{\text {Liq.R. }}+ \\
& +\beta_{5} \operatorname{exposure}_{\text {bank }_{i} \rightarrow \operatorname{sov}_{i}, t}^{k}+\epsilon_{\text {sov }_{i}, \text { bank }_{i}, t}
\end{aligned}
$$

Table 8: Factors associated with spillovers from sovereigns to banks in the same country

\begin{tabular}{lcccccc}
\hline \hline & \multicolumn{3}{c}{ High debt countries } & \multicolumn{3}{c}{ Low debt countries } \\
& $(1)$ & $(2)$ & $(3)$ & $(4)$ & $(5)$ & $(6)$ \\
\hline NPLs & $2.61^{* *}$ & $2.24^{* *}$ & $2.74^{* *}$ & -0.10 & -0.12 & -0.19 \\
& $(0.81)$ & $(0.81)$ & $(0.84)$ & $(0.18)$ & $(0.17)$ & $(0.17)$ \\
Capital & -1.38 & -0.80 & -2.49 & -0.06 & 0.34 & 0.41 \\
& $(0.77)$ & $(0.76)$ & $(1.31)$ & $(0.23)$ & $(0.23)$ & $(0.31)$ \\
Liquid assets & $-4.03^{* * *}$ & $-6.17^{* * *}$ & $-4.60^{* * *}$ & $-0.92^{* * *}$ & -0.11 & -0.43 \\
& $(0.48)$ & $(1.01)$ & $(0.69)$ & $(0.18)$ & $(0.29)$ & $(0.29)$ \\
Exposure domestic gov. debt & & $0.18^{* *}$ & & & $0.18^{* * *}$ & \\
& & $(0.07)$ & & & $(0.05)$ & \\
Exposure domestic NFCs & & & -0.04 & & & $0.05^{* *}$ \\
& & & $(0.03)$ & & & $(0.02)$ \\
\hline Time fixed effects? & Yes & Yes & Yes & Yes & Yes & Yes \\
Observations & 174 & 174 & 174 & 121 & 121 & 121 \\
$\mathrm{R}^{2}$ & 0.54 & 0.55 & 0.54 & 0.88 & 0.89 & 0.88 \\
Adjusted $\mathrm{R}^{2}$ & 0.37 & 0.38 & 0.37 & 0.80 & 0.82 & 0.81 \\
\hline \hline
\end{tabular}

The results in Table 8 suggest that, in line with the literature, the "balance sheet channel" plays a major role for both high and low debt countries, as underlined by the positive and significant coefficients associated with government bond exposures. On the contrary, and then affect domestic banks, e.g. through increased taxes and less consumer spending, or through a downgrade of non-financial companies. This last channel occurs because of the "rating channel": companies cannot have a better rating than their own sovereigns, so when the sovereign is downgraded this also affects private companies, Arezki et al. (2010).

${ }^{24} \mathrm{NPL}$ ratios of $3.6 \%, 15.2 \%$ for capital ratios, $80.0 \%$ for liquid assets to short term liabilities. 
the "real economy channel" seems to matter only for low debt countries (positive and significant coefficient for NFC exposures). Concerning the role of bank vulnerability, we find mixed results across country groups: For high debt countries, both higher NPL and lower liquidity ratios are significantly associated with higher domestic sovereign to bank spillovers in contrast to the capital ratio, which we find not to be significantly linked to the latter. For low debt countries, we find both NPL and capital ratios not to be significantly linked to spillovers, while we find lower liquidity ratios to be significantly associated with higher spillover only in one out of three regressions.

\section{Conclusion}

We propose a novel approach of the popular Diebold-Yilmaz framework by exploiting a SVAR-GARCH model that is statistically identified by the heteroskedasticity in the data. We show that this identification approach is attractive as it yields time-varying FEVDs based on the conditional variances of estimated structural errors. Moreover, we show that it is feasible to achieve economic identification between structural shocks and financial market variables in a nontrivial bijective relationship, even in a system of 16 variables. We show the advantages of this methodological contribution by comparing the results with other common identification approaches used in the time-varying spillover literature. Overall, the identification scheme is supported by the fact that the results outperform other models in terms of timeliness and narrative fit. Additionally, we show that the obtained pairwise spillovers match theoretical contagion channels.

This study has some limitations that could be addressed in future search. First, our identification approach relies on a constant $\boldsymbol{B}_{0}$ matrix over the full sample period ${ }^{25}$. In principal, this constraint can be relaxed by estimating the model on shorter subsamples,

\footnotetext{
${ }^{25}$ That implies that while varying shock sizes may generate time variation in spillovers, elasticities between the variables stay constant.
} 
for example defined on dates for which the researcher expects a structural break in interdependencies. While in Annex A.6 we allow for a single change in the $\boldsymbol{B}_{0}$ matrix, we leave a more profound analysis of this avenue for future research. Second, by imposing fewer constraints than previous models, the SVAR-GARCH could be applied to investigate contagion issues on time series that have been less considered in the literature, notably market liquidity data. 


\section{References}

Acharya, V., I. Drechsler, and P. Schnabl. 2014. A Pyrrhic Victory? Bank Bailouts and Sovereign Credit Risk. Journal of Finance 69:2689-2739.

Alexandre, H., F. Guillemin, and C. Refait-Alexandre. 2016. Crise de la dette souveraine dans l'Union Européenne: Transparence des banques et spreads de CDS. Revue Economique 67:1007-1035.

Alter, A., and A. Beyer. 2014. The dynamics of spillover effects during the European sovereign debt turmoil. Journal of Banking and Finance 42:134-153.

Alter, A., and Y. S. Schüler. 2012. Credit spread interdependencies of European states and banks during the financial crisis. Journal of Banking and Finance 36:3444-3468.

Ando, T., M. Greenwood-Nimmo, and Y. Shin. 2018. Quantile Connectedness: Modelling Tail Behaviour in the Topology of Financial Networks. SSRN Electronic Journal

Angeloni, C., and G. B. Wolff. 2012. Are banks affected by their holdings of government debt? Bruegel Working Paper 07.

Antolín-Díaz, J., and J. F. Rubio-Ramírez. 2018. Narrative sign restrictions for SVARs. American Economic Review 108:2802-2829.

Arezki, R., B. Candelon, and A. N. R. Sy. 2010. Bad news spreads. Finance and Development 47:36-37.

Bouakez, H., and M. Normandin. 2010. Fluctuations in the foreign exchange market:

How important are monetary policy shocks? Journal of International Economics 81:139-153.

Brunetti, C., J. H. Harris, S. Mankad, and G. Michailidis. 2019. Interconnectedness in the interbank market. Journal of Financial Economics 133:520-538. 
Buch, C. M., M. Koetter, and J. Ohls. 2016. Banks and sovereign risk: A granular view. Journal of Financial Stability 25:1-15.

Candelon, B., A. N. R. Sy, and R. Arezki. 2011. Sovereign Rating News and Financial Markets Spillovers: Evidence From the European Debt Crisis. IMF Working Papers $11: 1$.

Caporin, M., L. Pelizzon, F. Ravazzolo, and R. Rigobon. 2018. Measuring sovereign contagion in Europe. Journal of Financial Stability 34:150-181.

Claeys, P., and B. Vašíček. 2014. Measuring bilateral spillover and testing contagion on sovereign bond markets in Europe. Journal of Banking and Finance 46:151-165.

Coeuré, B. 2018. The international dimension of the ECB's asset purchase programme: an update. Tech. rep.

De Santis, R. A., and S. Zimic. 2018. Spillovers among sovereign debt markets: Identification through absolute magnitude restrictions. Journal of Applied Econometrics $33: 727-747$.

De Santis, R. A., and S. Zimic. 2019. Interest rates and foreign spillovers.

Demirer, M., F. X. Diebold, L. Liu, and K. Yilmaz. 2018. Estimating global bank network connectedness. Journal of Applied Econometrics 33:1-15.

Diebold, F. X., L. Liu, and K. Yilmaz. 2018. Commodity Connectedness. In E. Mendoza, S. D, and P. E (eds.), Monetary Policy and Global Spillovers: Mechanism, Effects and Policy Measures - An Overview. Santiago: Bank of Chile Central Banking Series.

Diebold, F. X., and K. Yilmaz. 2009. Measuring financial asset return and volatility spillovers, with application to global equity markets. Economic Journal 119:158-171.

Diebold, F. X., and K. Yilmaz. 2012. Better to give than to receive: Predictive directional measurement of volatility spillovers. International Journal of Forecasting 28:57-66. 
Diebold, F. X., and K. Yilmaz. 2014. On the network topology of variance decompositions: Measuring the connectedness of financial firms. Journal of Econometrics 182:119-134.

Dungey, M., G. Milunovich, and S. Thorp. 2010. Unobservable shocks as carriers of contagion. Journal of Banking and Finance 34:1008-1021.

Dungey, M., G. Milunovich, S. Thorp, and M. Yang. 2015. Endogenous crisis dating and contagion using smooth transition structural GARCH. Journal of Banking and Finance 58:71-79.

Ehrmann, M., and M. Fratzscher. 2017. Euro Area Government Bonds: Integration and Fragmentation During the Sovereign Debt Crisis. Journal of International Money and Finance 70:26-44.

Ehrmann, M., M. Fratzscher, and R. Rigobon. 2011. Stocks, bonds, money markets and exchange rates: Measuring international financial transmission. Journal of Applied Econometrics 26:948-974.

Engle, R. 2002. Dynamic conditional correlation: A simple class of multivariate generalized autoregressive conditional heteroskedasticity models. Journal of Business and Economic Statistics 20:339-350.

Fengler, M. R., and K. I. Gisler. 2015. A variance spillover analysis without covariances: What do we miss? Journal of International Money and Finance 51:174-195.

Fengler, M. R., and H. Herwartz. 2018. Measuring Spot Variance Spillovers when (Co)variances are Time-varying - The Case of Multivariate GARCH Models. Oxford Bulletin of Economics and Statistics 80:135-159.

Foerster, A. T., P. D. G. Sarte, and M. W. Watson. 2011. Sectoral versus aggregate 
shocks: A structural factor analysis of industrial production. Journal of Political Economy 119:1-38.

Fratzscher, M., and M. Rieth. 2019. Monetary Policy, Bank Bailouts and the SovereignBank Risk Nexus in the Euro Area*. Review of Finance 23:745-775.

Fry, R., and A. Pagan. 2011. Sign restrictions in structural vector autoregressions: A critical review. Journal of Economic Literature 49:938-960.

Geraci, M. V., and J. Y. Gnabo. 2018. Measuring Interconnectedness between Financial Institutions with Bayesian Time-Varying Vector Autoregressions. Journal of Financial and Quantitative Analysis 53:1371-1390.

Giudici, P., P. Sarlin, and A. Spelta. 2020. The Multivariate Nature of Systemic Risk: Direct and Common Exposures. Journal of Banking and Finance .

Greenwood, R., A. Landier, and D. Thesmar. 2015. Vulnerable banks. Journal of Financial Economics 115:471-485.

Greenwood-Nimmo, M., J. Huang, and V. H. Nguyen. 2019. Financial sector bailouts, sovereign bailouts, and the transfer of credit risk. Journal of Financial Markets 42:121-142.

Greenwood-Nimmo, M., V. H. Nguyen, and Y. Shin. 2017. What's Mine Is Yours: Sovereign Risk Transmission during the European Debt Crisis. SSRN Electronic Journal.

Grosse Steffen, C., and M. Podstawski. 2016. Ambiguity and Time-Varying Risk Aversion in Sovereign Debt Markets.

Hale, G., and J. A. Lopez. 2018. Monitoring Banking System Fragility with Big Data. Forthcoming: Journal of International Economics pp. 01-41. 
Kilian, L., and H. Lütkepohl. 2017. Structural vector autoregressive analysis. Cambridge University Press.

Korobilis, D., and K. Yilmaz. 2018. Measuring Dynamic Connectedness with Large Bayesian VAR Models. SSRN Electronic Journal .

Lanne, M., and P. Saikkonen. 2007. A Multivariate Generalized Orthogonal Factor GARCH Model. Journal of Business \&3 Economic Statistics 25:61-75.

Longstaff, F. A., J. Pan, L. H. Pedersen, and K. J. Singleton. 2011. How sovereign is sovereign credit risk? American Economic Journal: Macroeconomics 3:75-103.

Lütkepohl, H., and G. Milunovich. 2016. Testing for identification in SVAR-GARCH models. Journal of Economic Dynamics and Control 73:241-258.

Lütkepohl, H., and A. Netšunajev. 2017a. Structural vector autoregressions with heteroskedasticity: A review of different volatility models. Econometrics and Statistics $1: 2-18$.

Lütkepohl, H., and A. Netšunajev. 2017b. Structural vector autoregressions with heteroskedasticity: A review of different volatility models. Econometrics and Statistics $1: 2-18$.

Normandin, M., and L. Phaneuf. 2004. Monetary policy shocks:: Testing identification conditions under time-varying conditional volatility. Journal of Monetary Economics $51: 1217-1243$.

Pagano, M. 2018. The sovereign-bank nexus and the case for European safe bonds. In Finance and Investment: The European Case, pp. 149-156.

Pesaran, H., and Y. Shin. 1998. Generalized impulse response analysis in linear multivariate models. Economics Letters 58:17-29. 
Podstawski, M., and A. Velinov. 2018. The state dependent impact of bank exposure on sovereign risk. Journal of Banking and Finance 88:63-75.

Rigobon, R. 2003. Identification Through Heteroskedasticity. Review of Economics and Statistics 85:777-792.

Strohsal, T., and E. Weber. 2015. Time-varying international stock market interaction and the identification of volatility signals. Journal of Banking and Finance 56:28-36. 


\section{A Annex}

\section{A.1 Test for identification and estimated coefficients}

We rely on the original test proposed by Lanne and Saikkonen (2007) to test for the identification of $\boldsymbol{B}_{0}$. The recursive test applied here gives strong evidence for full identification of $\boldsymbol{B}_{0}$, see Table 9. For a more thorough description of the test, see Lütkepohl and Milunovich (2016). Note that the result of the test can be explained despite the reported low power of this latter, because (i) of the size of our dataset (ii) our 16 GARCH processes have a high persistence $\left(\gamma_{k}+g_{k}\right.$ close to $\left.0.9 \forall k\right)$ which tends to increase the power of the test.

Table 9: Test for identification in SVAR-GARCH

\begin{tabular}{cccc}
\hline$h$ under $H_{0}$ & $\mathrm{Q}_{1}(1)$ & df & $\mathrm{p}$-value \\
\hline 1 & 124.3405 & 1 & $<10^{-5}$ \\
2 & 113.4685 & 1 & $<10^{-5}$ \\
3 & 85.0733 & 1 & $<10^{-5}$ \\
4 & 66.6269 & 1 & $<10^{-5}$ \\
5 & 60.7231 & 1 & $<10^{-5}$ \\
6 & 46.2298 & 1 & $<10^{-5}$ \\
7 & 38.0658 & 1 & $<10^{-5}$ \\
8 & 35.8007 & 1 & $<10^{-5}$ \\
9 & 25.3033 & 1 & $<10^{-5}$ \\
10 & 16.2284 & 1 & $5.615 \mathrm{e}-05$ \\
11 & 13.3168 & 1 & 0.000263 \\
12 & 12.6034 & 1 & 0.000385 \\
13 & 517.7083 & 1 & $<10^{-5}$ \\
14 & 185.0355 & 1 & $<10^{-5}$ \\
15 & 154.8558 & 1 & $<10^{-5}$ \\
\hline
\end{tabular}




\section{A.2 CDS Data}

Table 10: List of banks used in bank sector CDS time series

\begin{tabular}{ll}
\hline Country & Banks \\
\hline BE & Dexia, KBC Bank \\
FR & BNP, Société Générale, Crédit Agricole \\
DE & Deutsche Bank, Commerzbank, DZ Bank, Landesbank Baden, Landesbank Hes- \\
& sen, HSH Nordbank, WESTLB \\
ES & BBVA, Banco pastor, Santander, Sabadell, Banco Popolar Espagnol \\
NL & Rabobank, ING Bank, SNS Bank \\
IT & Intesa, Unicredit Spa, Banca Montepaschi, Banco PPO Italiana, Unione di Banche \\
PT & Banco Comercial Portugues, Banco BPI, Caixa Geral \\
\hline
\end{tabular}


Figure A.1: CDS time series (bp, first difference)
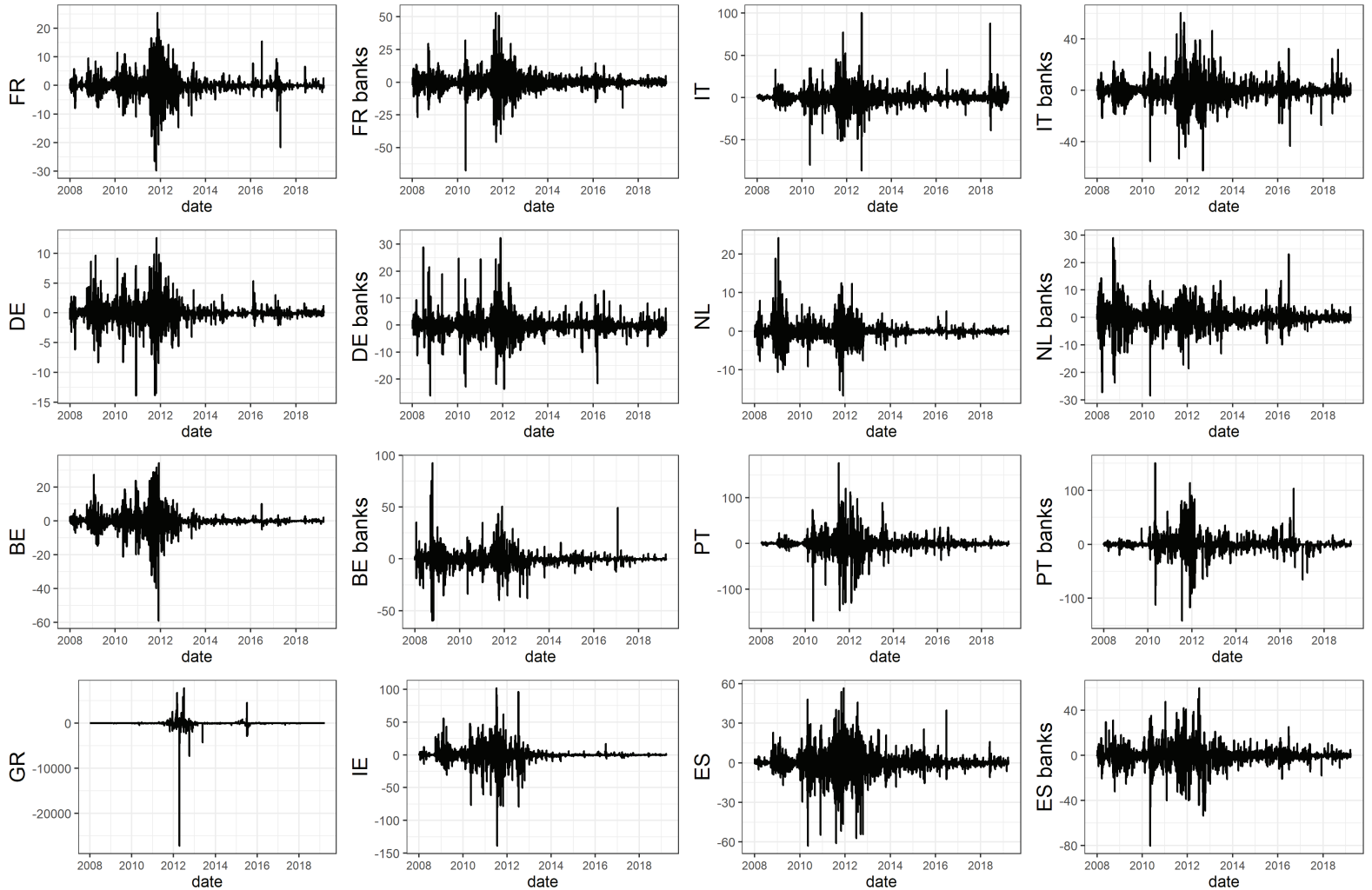

These graphs represent the raw time series of CDS used in the SVAR-GARCH (before the filtering of common shocks)

\section{A.3 List of Events}

Table 11: Historical Events

\begin{tabular}{llll}
\hline Variable & Date & Events & Source \\
\hline ES & $12 / 01 / 2010$ & Spain rows back on measures to enforce economic co-operation & FT \\
ES & $13 / 05 / 2010$ & Tough new austerity measures for Spain & FT \\
ES & $15 / 12 / 2010$ & Moody's puts Spain's Aa1 ratings on review for possible downgrade & FT \\
ES & $29 / 03 / 2011$ & Catalan leader Arturo Mas refuses to enforce austerity measures & FT \\
ES & $17 / 07 / 2011$ & Spain and Italy brace for bond market pressure & FT \\
ES & $03 / 01 / 2012$ & Warning over size of Spanish deficit & FT \\
ES & $08 / 05 / 2012$ & Spain set to spend billions on bank rescue & FT \\
ES & $29 / 08 / 2012$ & Catalonia set to call for 5 bn bailout & FT \\
ES & $09 / 11 / 2015$ & Catalunya vote for independeence & BBC
\end{tabular}


Table 11: Historical Events

\begin{tabular}{|c|c|c|c|}
\hline Variable & Date & Events & Source \\
\hline ES & $27 / 10 / 2017$ & Catalan sparks Madrid showdown & FT \\
\hline ES & $27 / 05 / 2018$ & Spain upheaval deepens Italy market jitters & $\mathrm{FT}$ \\
\hline $\mathrm{BE}$ & $14 / 07 / 2008$ & Belgium government resigns & le Monde \\
\hline $\mathrm{BE}$ & $07 / 06 / 2010$ & Uncertainty on Belgium debt (elections coming) & $\mathrm{FT}$ \\
\hline $\mathrm{BE}$ & $14 / 12 / 2010$ & SP downgrades Belgium perspective & $\mathrm{CNBC}$ \\
\hline $\mathrm{BE}$ & $22 / 11 / 2011$ & Belgian spreads enlarge & $\mathrm{FT}$ \\
\hline $\mathrm{BE}$ & $25 / 11 / 2011$ & SP downgrades Belgium & FT \\
\hline $\mathrm{BE}$ & $01 / 03 / 2012$ & Belgian State buys back Dexia & Les Echos \\
\hline IT & $01 / 12 / 2010$ & "Premiums that Italy pay hit fresh highs" & FT \\
\hline IT & $30 / 06 / 2012$ & $\begin{array}{l}\text { Markets rebound following EU deal "the agreement allow }(. . .) \text { to buy Italian } \\
\text { sovereign bonds" }\end{array}$ & FT \\
\hline IT & $28 / 10 / 2013$ & Bond yields fall to four-month low as Italy sells 2 -year debt & Nasdaq \\
\hline IT & $15 / 04 / 2014$ & $\begin{array}{l}\text { "On April 15th yields on ten-year Italian-government bonds fell to } 3.11 \% \text {, } \\
\text { the lowest on record" }\end{array}$ & The Economist \\
\hline IT & $30 / 05 / 2018$ & Italy election crisis spreads as central bank chief warns investor trust is fading & FT \\
\hline IT & $19 / 12 / 2018$ & Italian bonds and stocks rally as government comes closer to EU pact & FT \\
\hline GR & $09 / 03 / 2012$ & ISDA declares Greece in default (impact on CDS, restructuring) & Reuters \\
\hline GR & $09 / 04 / 2012$ & CDS decrease after Greece restructuring & The Economist \\
\hline GR & $19 / 06 / 2012$ & EZ's Greek poll honeymoon short lived & $\mathrm{FT}$ \\
\hline GR & $21 / 05 / 2013$ & Significant decrease in Greek sovereign CDS series & \\
\hline GR & $11 / 07 / 2015$ & EZ finance ministers prepare to decide Greece's fate & FT \\
\hline $\mathrm{PT}$ & $27 / 04 / 2010$ & Portugal rating downgraded & $\mathrm{CNN}$ \\
\hline $\mathrm{PT}$ & $29 / 03 / 2011$ & Portugal rating downgraded & $\mathrm{FT}$ \\
\hline $\mathrm{PT}$ & $06 / 07 / 2011$ & Portugal rating blow & $\mathrm{FT}$ \\
\hline $\mathrm{PT}$ & $18 / 01 / 2012$ & Moody's warns of second rescue for Portugal & FT \\
\hline $\mathrm{PT}$ & $07 / 02 / 2012$ & Speculation on Portugal debt restructuring & Les Echos \\
\hline $\mathrm{PT}$ & $09 / 03 / 2012$ & Renew speculation on Portugal debt & Reuters \\
\hline $\mathrm{PT}$ & $02 / 07 / 2013$ & Portuguese government at risk of collapse as foreign minister resigns & Telegraph \\
\hline $\mathrm{PT}$ & $10 / 11 / 2015$ & Confidence vote againt government, potential left-wing coalition & Business Insider \\
\hline $\mathrm{PT}$ & $08 / 02 / 2016$ & Portugal-Germany Yield Spread Widens to Most Since 2014 & Bloomberg \\
\hline IE & $11 / 02 / 2009$ & $\begin{array}{l}\text { Recapitalisation was carried out at Ireland's two largest banks, Allied Irish } \\
\text { Bank (AIB) and Bank of Ireland (BoI) }\end{array}$ & FT \\
\hline IE & $28 / 04 / 2010$ & Marked increase in Irish 2-year bond yields & The Irish Times \\
\hline IE & $18 / 07 / 2011$ & Record high of Irish CDS in our time series & \\
\hline IE & $06 / 07 / 2012$ & Ireland comes back on sovereign debt markets & FT \\
\hline FR & $11 / 08 / 2011$ & Focus of EZ crisis turns to France & $\mathrm{FT}$ \\
\hline FR & $10 / 11 / 2011$ & $\begin{array}{l}\text { Standard \& Poor's mistakenly announced the downgrade of France's top } \\
\text { credit rating on Thursday }\end{array}$ & Reuters \\
\hline FR & $14 / 01 / 2012$ & SP downgrades France and Austria & FT \\
\hline FR & $22 / 02 / 2017$ & Highest DE-FR spread since 2012 & $\mathrm{CNBC}$ \\
\hline FR & $28 / 04 / 2017$ & France CDS bounce back after election & IHS Markit \\
\hline NL & $09 / 10 / 2008$ & Governement capital injections into banks & BIS \\
\hline NL & $26 / 01 / 2009$ & Bank comprehensive rescue plans (asset insurance) & BIS \\
\hline NL & $14 / 01 / 2012$ & SP puts Netherlands sovereign on negative outlook & Reuters \\
\hline NL & $23 / 04 / 2012$ & PM Rutte resigns after austerity talks & The Guardian \\
\hline NL & $20 / 08 / 2013$ & Netherland's top rating is affirmed at Fitch amid debt warning & Bloomberg \\
\hline
\end{tabular}


Table 11: Historical Events

\begin{tabular}{|c|c|c|c|}
\hline Variable & Date & Events & Source \\
\hline $\mathrm{DE}$ & $07 / 05 / 2010$ & German Parliament approves Greek rescue & NYT \\
\hline $\mathrm{DE}$ & $29 / 11 / 2010$ & German credit risk jumps to highest since may, debt swaps show & Bloomberg \\
\hline $\mathrm{DE}$ & $09 / 02 / 2016$ & $\begin{array}{l}\text { Five-year sovereign German CDS rose to almost } 22 \text { bps due to hedging ac- } \\
\text { tivity }\end{array}$ & Reuters \\
\hline DE banks & $28 / 04 / 2009$ & Profit-taking undermines Deutsche Bank & FT \\
\hline DE banks & $19 / 04 / 2010$ & $\begin{array}{l}\text { Bank dividend payments reach record low: Deutsche Bank, plans to pay a } \\
\text { dividend of } 0.75 \text { for } 2009 \text {, up from } 0.50 \text { in } 2008 \text {, but still small compared } \\
\text { with earnings per share of } 7.59\end{array}$ & FT \\
\hline DE banks & $11 / 01 / 2011$ & Concerns rise over German bank levy & FT \\
\hline DE banks & $10 / 03 / 2011$ & Sale of stake in Deutsche AM puzzles analysts & FT \\
\hline DE banks & $28 / 07 / 2011$ & $\begin{array}{l}\text { Deutsche Bank net revenues in its corporate and investment banking arm fell } \\
27 \text { per cent in the second quarter }\end{array}$ & FT \\
\hline DE banks & $10 / 09 / 2011$ & Commerzbank hit by $760 \mathrm{~m}$ Greek writedown & FT \\
\hline DE banks & $24 / 11 / 2011$ & Deutsche bank needs 2 bln to meet EBA's conditions & EBA \\
\hline DE banks & $07 / 12 / 2011$ & SP placed the credit Deutsche Bank and Commerzban under review & Deutsche Welle \\
\hline DE banks & $24 / 01 / 2012$ & Commerzbank buoyant as investors back capital plan & FT \\
\hline DE banks & $10 / 03 / 2016$ & Deutsche and UBS defeated in UK tax avoidance case over bankers' bonuses & $\mathrm{BBC}$ \\
\hline DE banks & $03 / 05 / 2017$ & HNA raises stake in Deutsche Bank to nearly $10 \%$ & FT \\
\hline DE banks & $01 / 06 / 2018$ & SP downgrades Deutsche Bank & FT \\
\hline DE banks & $04 / 12 / 2018$ & Investor fear raids will hit DB turnaround & FT \\
\hline FR banks & $06 / 05 / 2010$ & $\begin{array}{l}\text { BNP Paribas and Société Générale in suffering as the costs of insuring them- } \\
\text { selves against default rises }\end{array}$ & FT \\
\hline FR banks & $12 / 08 / 2011$ & French Short-selling ban brings relief for banks & FT \\
\hline FR banks & $13 / 09 / 2011$ & BNP Bank executive says they can no longer borrow USD & WSJ \\
\hline FR banks & $14 / 10 / 2011$ & Big European CDS such as France's BNP Paribas spiked to 291bp & FT \\
\hline FR banks & $07 / 11 / 2011$ & BNP stock price plunges compared to CAC $40 \mathrm{p}$ & Les Echos \\
\hline FR banks & $30 / 11 / 2011$ & SocGen, UniCredit and BNP lose some of Monday's gains & FT \\
\hline FR banks & $12 / 02 / 2016$ & SocGen battles to hit targets amid low rates and volatility & FT \\
\hline FR banks & $11 / 06 / 2018$ & France tells its banks to set aside more capital & FT \\
\hline IT banks & $17 / 08 / 2011$ & $\begin{array}{l}\text { Shares in Italy's biggest retail bank Intesa Sanpaolo were at one point sus- } \\
\text { pended for excessive losses "European banks at centre of sell-off" }\end{array}$ & FT \\
\hline IT banks & $30 / 11 / 2011$ & $\begin{array}{l}\text { European banks' junior debt under review, including a number of Italian } \\
\text { banks "European banks' junior debt under review" }\end{array}$ & FT \\
\hline IT banks & $01 / 02 / 2013$ & $\begin{array}{l}\text { Monte dei Paschi di Siena asks for } 3.9 \mathrm{bn} \text { bailout amid scandal over loss- } \\
\text { making derivatives contracts and alleged fraud }\end{array}$ & the Guardian \\
\hline IT banks & $11 / 06 / 2016$ & Italian banking crisis, heightened by European financial stress tests & FT \\
\hline IT banks & $27 / 06 / 2016$ & Italian banks struggling "Italy resurrects plans to rescue struggling banks" & FT \\
\hline IT banks & $04 / 05 / 2017$ & Monte Paschi CDS time series spike & \\
\hline IT banks & $29 / 11 / 2017$ & $\begin{array}{l}\text { European Central Bank has redoubled warnings that the state of EZ banks } \\
\text { is a threat to the region's economic recovery, IT banks with biggest problem } \\
\text { of sour loans }\end{array}$ & FT \\
\hline IT banks & $31 / 08 / 2018$ & UniCredit and Intesa Sanpaolo fall on news of increased political uncertainty & FT \\
\hline PT banks & $06 / 05 / 2010$ & $\begin{array}{l}\text { Spectre of counterparty risk, focused attention on to smaller banks in Por- } \\
\text { tugal and Spain }\end{array}$ & FT \\
\hline PT banks & $19 / 07 / 2011$ & BCP fails Espírito Santo Financia almost fails EBA stress test & EBA \\
\hline PT banks & $30 / 11 / 2011$ & BCP's CDS arrive at record level after Fitch downgrade of covered bonds & Bloomberg \\
\hline
\end{tabular}


Table 11: Historical Events

\begin{tabular}{|c|c|c|c|}
\hline Variable & Date & Events & Source \\
\hline PT banks & $16 / 02 / 2012$ & $\begin{array}{l}\text { Moodys downgrades state guaranteed debt issued by } \mathrm{BCP} \text { from } \mathrm{Ba} 2 \text { to } \mathrm{Ba} 3 \\
\text { with negative outlook }\end{array}$ & FT \\
\hline PT banks & $18 / 08 / 2016$ & Portuguese bonds under pressure after rating agency's warning & FT \\
\hline PT banks & $10 / 01 / 2017$ & Fosun to increase its stake in Millennium BCP to $30 \%$ & $\mathrm{FT}$ \\
\hline PT banks & $28 / 03 / 2017$ & CDS spread of BCP drops sharply & \\
\hline BE banks & $18 / 09 / 2008$ & Speculative rumors against Fortis & La Libre Belgique \\
\hline BE banks & $30 / 09 / 2008$ & Dexia bailed out & The Guardian \\
\hline BE banks & $15 / 10 / 2008$ & $\begin{array}{l}\text { Bank rally, Dexia, the Franco-Belgian bank whose borrowings have already } \\
\text { had to be guaranteed, dismissed rumours that it faced impending nationali- } \\
\text { sation by the Belgian government }\end{array}$ & FT \\
\hline BE banks & $29 / 12 / 2008$ & $\mathrm{KBC}$ loses 1 billion on CDOs & La Libre Belgique \\
\hline BE banks & $30 / 09 / 2011$ & $\begin{array}{l}\text { Belgium market authority ends short selling ban on Belgian financial insti- } \\
\text { tutions }\end{array}$ & Fed NY \\
\hline BE banks & $05 / 10 / 2011$ & Dexia shares suspended as break-up takes shape & $\mathrm{FT}$ \\
\hline BE banks & $02 / 11 / 2012$ & $\begin{array}{l}\text { Three banks - Lloyds Banking Group, Commerzbank and Dexia - were } \\
\text { dropped from the GSifi list }\end{array}$ & FT \\
\hline BE banks & $29 / 12 / 2012$ & European commission validates Dexia rescue plan & Le Monde \\
\hline BE banks & $25 / 01 / 2017$ & Repricing of Dexia CDS & FT \\
\hline ES banks & $14 / 01 / 2011$ & Spain seeks to show that it is not another Ireland & FT \\
\hline ES banks & $13 / 07 / 2011$ & Spanish bank IPOs under threat & FT \\
\hline ES banks & $09 / 08 / 2011$ & $\begin{array}{l}\text { Investors turn agains spanish financials as they bet against the value of what } \\
\text { they see as fragile institutions }\end{array}$ & FT \\
\hline ES banks & $26 / 09 / 2011$ & $\begin{array}{l}\text { News about bank rescue plan: ECB expected to boost bank liquidity. Span- } \\
\text { ish banks affected in particuliar }\end{array}$ & FT \\
\hline ES banks & $28 / 03 / 2012$ & EU underlines that Spanish banks need to bailout & FT \\
\hline ES banks & $09 / 07 / 2012$ & $\begin{array}{l}\text { Spanish bank bailout talks. Spain to Accept Rescue From Europe for Its } \\
\text { Ailing Banks }\end{array}$ & NYT \\
\hline ES banks & $16 / 10 / 2012$ & Spanish banks rally on hope Madrid ready to request aid & FT \\
\hline ES banks & $25 / 03 / 2013$ & $\begin{array}{l}\text { Bankia leads falls across big lenders after } \mathrm{EZ} \text { comment to toughen bank } \\
\text { regime }\end{array}$ & $\mathrm{FT}$ \\
\hline ES banks & $21 / 01 / 2016$ & Market sentiment turns sharply against Spain's banking sector & $\mathrm{FT}$ \\
\hline ES banks & $08 / 06 / 2017$ & Emergency funds failed to save Banco Popular from death spiral & $\mathrm{FT}$ \\
\hline ES banks & $05 / 12 / 2017$ & Strong drop of CDS of Banco Popular & \\
\hline ES banks & $26 / 09 / 2018$ & Banco Santander changes its chief executive & FT \\
\hline NL banks & $30 / 09 / 2008$ & The Belgian-Dutch Fortis faces state rescue & Reuters \\
\hline NL banks & $19 / 10 / 2008$ & ING receives 10 billion from Dutch government & NYT \\
\hline NL banks & $26 / 03 / 2009$ & Fortis Bank Nederland posts 25.11 billion loss & Reuters \\
\hline NL banks & $16 / 01 / 2012$ & ING benefits from ING gains from Netherlands' credit rating & FT \\
\hline NL banks & $13 / 06 / 2012$ & ING to pay USD $619 \mathrm{~m}$ to settle sanctions case & $\mathrm{FT}$ \\
\hline NL banks & $09 / 07 / 2012$ & Former Rabobank traders fired in LIBOR-scandale & Observer \\
\hline
\end{tabular}




\section{A.4 IRF assumptions}

An additional advantage of our econometric framework is that it imposes less restrictions on the impulse response functions (IRFs) compared to other contagion-models. More specifically, Cholesky-identified SVARs, as used in VAR Cholesky and DCC Cholesky, postulate a recursive structure of the IRFs. Generalized impulse response functions, as used in VAR GIRF, impose that the IRF of a one-unit shock $i$ on variable $j$ has the same initial impact as an IRF from shock $j$ to variable $i$. Eventually the same criticism applies also to the orthogonalization in Fengler and Herwartz (2018) as used for the model DCC Fengler -see demonstrations below. On the reverse, the SVAR-GARCH framework does not impose such a structure (Lütkepohl and Netšunajev (2017b)). Therefore the leveldifferences observed on Figure 3 may come from the overly strong assumptions of the competing models, over- or underestimating the spillovers.

Why do the identifications used in VAR GIRF and in DCC Fengler assume symmetrical IRFs? A usual VAR-analysis begins with the reduced form VAR (Equation 6), with the objective to go to the structural form of Equation 5. Under covariance stationarity, Equation 6 is equivalent to its moving average representation:

$$
\boldsymbol{Y}_{t}=\sum_{i=0}^{\infty} \boldsymbol{\Phi}_{i} \boldsymbol{\mu}_{t-i}
$$

Which can be rewritten in its structural form:

$$
\boldsymbol{Y}_{t}=\sum_{i=0}^{\infty}\left(\boldsymbol{\Phi}_{i} \boldsymbol{B}_{0}\right)\left(\boldsymbol{B}_{0}^{-1} \boldsymbol{\mu}_{t-i}\right)=\sum_{i=0}^{\infty} \boldsymbol{\Theta}_{i} \boldsymbol{\epsilon}_{t-i}
$$

Generally speaking, the IRF of a vector shock $\boldsymbol{\delta}=\left(\delta_{1}, \ldots, \delta_{n}\right)$ on $\boldsymbol{Y}_{t}$ is defined, at horizon $h$ and with $\boldsymbol{\Omega}_{t-1}$ the information set at $t$, as: 


$$
\operatorname{IRF}\left(h, \boldsymbol{\delta}, \boldsymbol{\Omega}_{t-1}\right)=E\left(\boldsymbol{Y}_{t+h} \mid \boldsymbol{\epsilon}_{t}=\boldsymbol{\delta}, \boldsymbol{\Omega}_{t-1}\right)-E\left(\boldsymbol{Y}_{t+h} \mid \boldsymbol{\Omega}_{t-1}\right)
$$

Due to the orthogonality of the structural shocks, one uses $\boldsymbol{\delta}=\left(0, \ldots, 0, \delta_{j}, 0, \ldots, 0\right)$ in order to consider the impact of a single shock. In that case we get, with $\boldsymbol{e}_{j}$ a vertical vector full of zeros apart for its $j^{\text {th }}$ element that is equal to $1: \operatorname{IRF}\left(h, \boldsymbol{\delta}, \boldsymbol{\Omega}_{t-1}\right)=$ $\boldsymbol{\Phi}_{h} \boldsymbol{B}_{0} \boldsymbol{\delta}=\boldsymbol{\Phi}_{h} \boldsymbol{B}_{0} \boldsymbol{e}_{j} \delta_{j}$

In our SVAR-GARCH setting, $\boldsymbol{B}_{0}$ is identified by heteroskedasticity and by economic identification (with $\boldsymbol{\Sigma}_{\epsilon}$ and $\boldsymbol{\Sigma}_{\mu}$ evolving over time and being equal to, respectively, $\boldsymbol{\lambda}_{t \mid t-1}$ and $\boldsymbol{\Sigma}_{\mu, t \mid t-1}$, Equation 13). This identification strategy does not impose any structure on the IRFs. Conversely, in Diebold and Yilmaz (2009), $\boldsymbol{B}_{0}$ is identified by using the Cholesky decomposition of $\boldsymbol{\Sigma}_{\mu}$ with $\boldsymbol{B}_{0}^{-1} \boldsymbol{B}_{0}^{-1 \prime}=\boldsymbol{\Sigma}_{\mu}$ as in the first equation of Equation 8. Although convenient, this orthogonalization imposes a recursive structure in the Data Generating Process as $\boldsymbol{B}_{0}$ is then lower-triangular.

Identification by GIRF works differently since, instead of considering structural shocks,

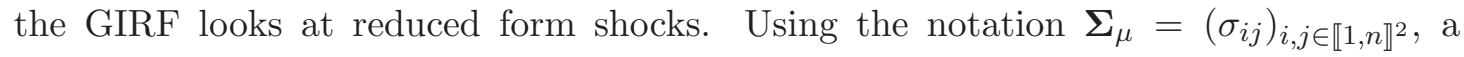
one standard deviation shock $j$ and the same remaining notations, the GIRF is defined as:

$$
\operatorname{GIRF}\left(h, \sigma_{j j} \boldsymbol{e}_{j}, \boldsymbol{\Omega}_{t-1}\right)=E\left(\boldsymbol{Y}_{t+h} \mid \boldsymbol{\mu}_{t}=\sigma_{j j} \boldsymbol{e}_{j}, \boldsymbol{\Omega}_{t-1}\right)-E\left(\boldsymbol{Y}_{t+h} \mid \boldsymbol{\Omega}_{t-1}\right)
$$

If one assumes that $\mu_{t} \sim N\left(\mathbf{0}, \boldsymbol{\Sigma}_{\mu}\right)$, then we can write (see Pesaran and Shin (1998)):

$$
E\left(\boldsymbol{\mu}_{t} \mid \mu_{j t}=\sigma_{j j}\right)=\left[\left(\sigma_{1 j}, \ldots, \sigma_{m j}\right)^{\prime} \sigma_{j j}^{-1}\right] \sigma_{j j}=\boldsymbol{\Sigma}_{\mu} \boldsymbol{e}_{j}
$$

So that the impact of a one standard deviation $j$ shock on variable $i$ at horizon 0 is 
(with Equation A.29):

$$
\operatorname{GIRF}_{i}\left(0, \sigma_{j j} \boldsymbol{e}_{j}, \boldsymbol{\Omega}_{t-1}\right)=\boldsymbol{e}_{i}^{\prime} \boldsymbol{\Phi}_{0} \boldsymbol{\Sigma}_{\mu} \boldsymbol{e}_{j}
$$

As $\boldsymbol{\Phi}_{0}=\boldsymbol{I}$ we get:

$$
\operatorname{GIRF}_{i}\left(0, \sigma_{j j} \boldsymbol{e}_{j}, \boldsymbol{\Omega}_{t-1}\right)=\boldsymbol{e}_{i}^{\prime} \boldsymbol{\Sigma}_{\mu} \boldsymbol{e}_{j}=\sigma_{i j}=\sigma_{i j}=\operatorname{GIRF_{j}}\left(0, \sigma_{i i} \boldsymbol{e}_{i}, \boldsymbol{\Omega}_{t-1}\right)
$$

Similarly, the identification strategy of Fengler and Herwartz (2018) used in DCC Fengler yields also symmetric IRFs on impact. This is because the time-varying matrices $\boldsymbol{B}_{0, t}^{-1}$ (and hence $\boldsymbol{B}_{0, t}$ ) are symmetric as, $\forall t$ and knowing that $\boldsymbol{\Lambda}_{t}$ is diagonal and therefore symmetric:

$$
\left(\boldsymbol{B}_{0, t}^{-1}\right)^{\prime}=\left(\boldsymbol{\Gamma}_{t} \boldsymbol{\Lambda}_{t}^{1 / 2} \boldsymbol{\Gamma}_{t}^{\prime}\right)^{\prime}=\boldsymbol{\Gamma}_{t}\left(\boldsymbol{\Gamma}_{t} \boldsymbol{\Lambda}_{t}^{1 / 2}\right)^{\prime}=\boldsymbol{\Gamma}_{t} \boldsymbol{\Lambda}_{t}^{1 / 2} \boldsymbol{\Gamma}_{t}^{\prime}=\boldsymbol{B}_{0, t}^{-1}
$$

To conclude, identification with GIRFs or the identification of Fengler and Herwartz (2018) impose a symmetric structure of impulse responses upon impact while identification by Cholesky assumes a recursive one. These assumptions may be controversial when it comes to financial data which tend to respond rapidly to shocks and where variables react asymmetrically to each other.

\section{A.5 Data sources OLS regressions}

- Similar Business Cycle : the quarterly squared difference between country i and country j's GDP growth (multiplied by $(-1)$ so that a higher number indicates more similar tendencies) [this is similar to De Santis and Zimic (2018), albeit De Santis and Zimic (2018) sum over over time as they focus on cross sectional effects];

Source: Eurostat 
- Similar D/GDP : Same approach for quarterly D/GDP ratios (multiplied by (-1) so that a higher number indicates more similar tendencies); Source: IMF

- Trade exposure: $\frac{\text { Exports }_{j \rightarrow i}}{\text { Total exports }_{j}}$; Source: IMF

- Investment exposure: $\frac{\text { International investment } t_{j \rightarrow i}}{\text { Total International investment } j} ;$ Source: Eurostat

- 'Similar NPLs : the quarterly squared difference between banking sector i and banking sector j's NPLs (multiplied by $(-1)$ so that a higher number indicates more similar tendencies); Source: IMF Financial Soundness indicators and SNL

- Same approach for capital ratios; Source: IMF Financial Soundness indicators and SNL

- 'Similar portfolio: In a first step we construct from CBS data portfolio vectors per quarter for each banking sector as in Greenwood et al. (2015): a vector with the holdings of sovereign debt, non-bank financial institutions, households and non-financial corporations; for a large range of counterparty countries. We then express all portfolio items in \% to total assets. And finally, we calculate the sum of the squared difference of those portfolio; Source: BIS CBS

- Bank claim exposure: $\frac{\text { Bank claims of country } \mathrm{j} \text { vis-a-vis country } \mathrm{i}}{\sum_{i} \text { Bank claims of country j vis-a-vis country } \mathrm{i}}$, Source: BIS CBS

- NPLs, capital ratios (regulatory Capital to Risk-Weighted Assets) and liquidity ratios (Liquid Assets to Short Term Liabilities) of banking systems in percent; Source: IMF Financial Soundness indicators and SNL

- Exposure domestic government debt: $\frac{\text { Sovereign debt of country i held by banking system j }}{\text { Total assets of banking system j }}$ Source: IMF IFS

- Exposure domestic government NFCs: $\frac{\text { Non-bank assets of country i held by banking system j }}{\text { Total assets of banking system j }}$ Source: IMF IFS

- 'Sovereign exposure' : $\frac{\text { Sovereign debt of country } j \text { held by } i}{\text { Total sovereign debt of country } j}$, Source: BIS CBS 
- 'Nonbank exposure' : $\frac{\text { Liabilities of country j's non-banks held by i }}{\text { Total Liabilities of country j's non-banks }}$ Source: BIS CBS

- Debt to GDP, Current account, GDP growth in \%, Source: Eurostat, OECD and IMF

\section{A.6 Robustness checks}

We perform several checks to assess the robustness of our results. First, with regards to the exogenous regressors: in our main specification we follow Alter and Beyer (2014) and include a significant number of exogenous variables to account for the strong comovement between CDS spreads. However, one might argue that some of them are endogenous to the sovereign and bank CDS. Therefore, we also estimate the model with a more parsimonious set of exogenous variables. In line with De Santis and Zimic (2018) we consider as alternative exogenous variables: oil prices, global macro news provided by Citibank, as well as US and UK CDS spreads. The upper part of Figure A.2 represents total spillover indices $S^{H}$ from different specifications, including our main one ("SVARGARCH"). As can be seen on the graph, some level changes are observable at the beginning of the estimation period, but overall the different indices evolve in a parallel manner.

Second, as exposed in Section 3.2, we assume a constant $\boldsymbol{B}_{0}$ in our study. Some authors argued that the increase in CDS-correlation during the EZ debt crisis came mainly from changes in volatility and not in propagation mechanisms (Caporin et al. (2018)), but this point is disputed (De Santis and Zimic (2018)). To evaluate the robustness of our results to changes in the estimation period, we estimate our model on different subsamples. In line with Ehrmann and Fratzscher (2017), we define two subperiods: a crisis period starting at the beginning of our sample until 01/10/2012 ${ }^{26}$, and a post-crisis period

\footnotetext{
${ }^{26}$ Corresponding to the announcements of the implementation details of the ECB OMT-program
} 
running from 01/10/2012 to the end of our sample ${ }^{27}$. The bottom part of Figure A.2 exhibits total spillover indices $S^{H}$ from the models estimated over the all sample, or over the two subsamples. Here again, apart from level differences on years 2013-2014, our results appear robust to changes in estimation period.

\footnotetext{
${ }^{27}$ Note that Ehrmann and Fratzscher (2017) use 3 smaller subperiods, with a "crisis period" for the Greek turmoil that starts in March 2010 and ends in March 2012, and a "post-crisis period" that starts in October 2012. However, to build the total spillover indices $S^{H}$, we need the exact identification underlined in Section 5.1.1, i.e. being able to assign each shock to a single variable. This identification is not granted for any subsample, and is hard to achieve on short time intervals. Thus, on Figure A.2 we rely on a large "crisis period" so as to obtain this identification.
} 
Figure A.2: Robustness graphs
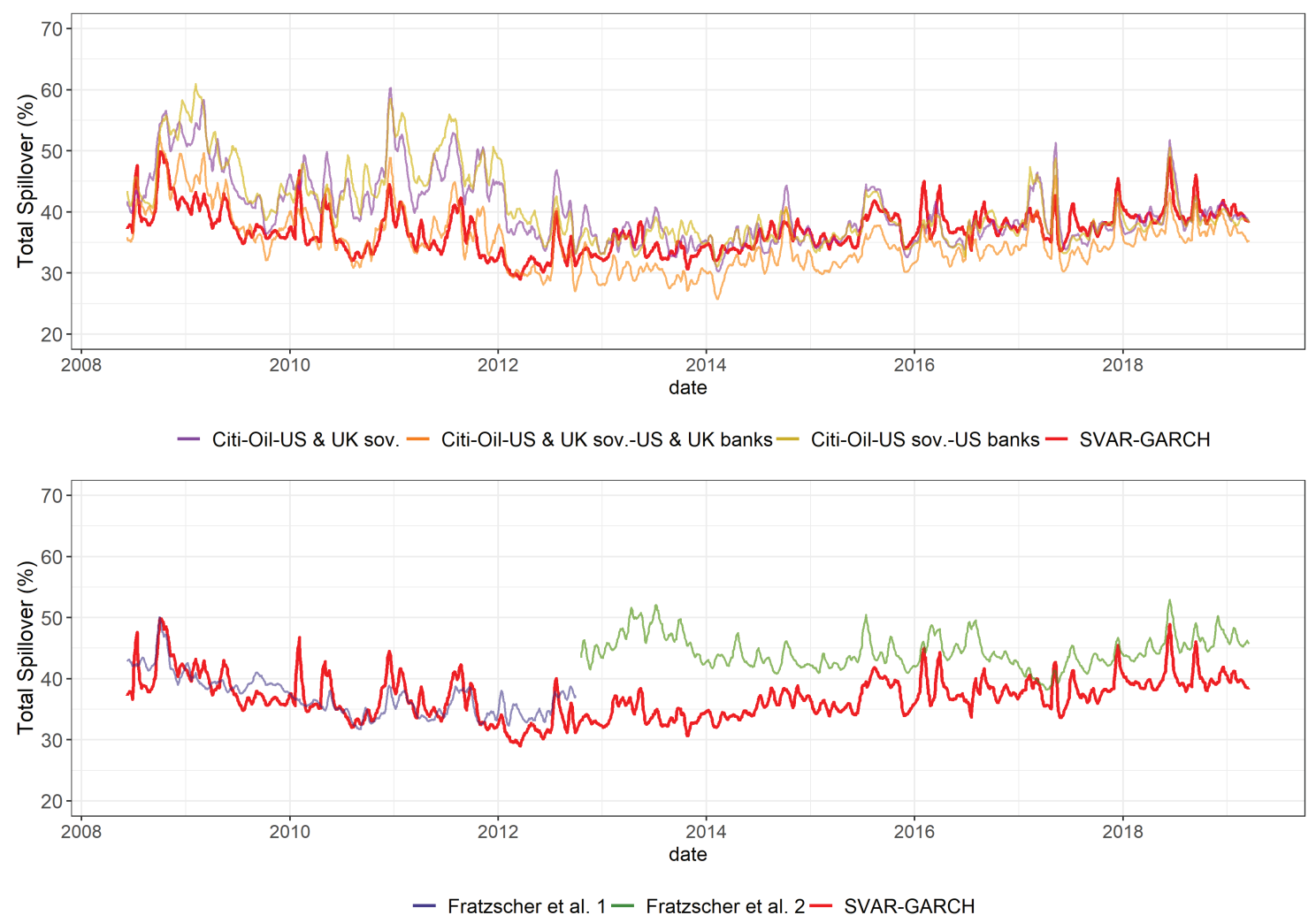

The different lines represent the Total Spillover indices $S^{H}$ built from our main specification ("SVAR-GARCH") as well as from the other specifications outlined above. For the upper part of the graph, the different indices are named according to the exogenous variables included (Oil price, Macro news from Citibank, US and UK bank or sovereign CDS). For the bottom part of the graph, the different indices represent our main specification estimated on subsamples (before and after 01/10/2012 as outlined in Ehrmann and Fratzscher (2017)). For readability we show 10 day moving averages of the indices. 